University of Nebraska - Lincoln

DigitalCommons@University of Nebraska - Lincoln

2-8-2001

\title{
Gap filling strategies for defensible annual sums of net ecosystem exchange
}

\author{
Eva Falge \\ SPM, University of California, Berkeley, Berkeley, CA \\ Dennis D. Baldocchi \\ University of California, Berkeley, baldocchi@berkeley.edu \\ Richard Olson \\ Environmental Science Division, Oak Ridge National Laboratory, Oak Ridge, TN, USA \\ Peter Anthoni \\ Richardson Hall, Oregon State University, Corvallis, OR \\ Marc Aubinet \\ Unité de Physique, Faculté des Sciences Agronomiques de Gembloux, B-50 30 Gembloux, Belgium \\ See next page for additional authors \\ Follow this and additional works at: https://digitalcommons.unl.edu/natrespapers \\ Part of the Natural Resources and Conservation Commons
}

Falge, Eva; Baldocchi, Dennis D.; Olson, Richard; Anthoni, Peter; Aubinet, Marc; Bernhofer, Christian; Burba, George; Ceulemans, Reinhart; Clement, Robert; Dolman, Han; Grainer, Andre; Grunwald, Thomas; Hollinger, David; Jensen, Niels-Otto; Katul, Gabriel; Keronen, Petri; Kowalski, Andrew; Ta Lai, Chun; Law, Beverly E.; Meyers, Tilden; Moncrieff, Jon; Moors, Eddy; Munger, J. William; Pilegaard, Kim; Rannik, Ullar; Rebmann, Corinna; Suyker, Andrew E.; Tenhunen, John; Tu, Kevin; Verma, Shashi; Vesala, Timo; Wilson, Kell; and Wofsy, Steve, "Gap filling strategies for defensible annual sums of net ecosystem exchange" (2001). Papers in Natural Resources. 53.

https://digitalcommons.unl.edu/natrespapers/53

This Article is brought to you for free and open access by the Natural Resources, School of at DigitalCommons@University of Nebraska - Lincoln. It has been accepted for inclusion in Papers in Natural Resources by an authorized administrator of DigitalCommons@University of Nebraska - Lincoln. 


\section{Authors}

Eva Falge, Dennis D. Baldocchi, Richard Olson, Peter Anthoni, Marc Aubinet, Christian Bernhofer, George Burba, Reinhart Ceulemans, Robert Clement, Han Dolman, Andre Grainer, Thomas Grunwald, David Hollinger, Niels-Otto Jensen, Gabriel Katul, Petri Keronen, Andrew Kowalski, Chun Ta Lai, Beverly E. Law, Tilden Meyers, Jon Moncrieff, Eddy Moors, J. William Munger, Kim Pilegaard, Ullar Rannik, Corinna Rebmann, Andrew E. Suyker, John Tenhunen, Kevin Tu, Shashi Verma, Timo Vesala, Kell Wilson, and Steve Wofsy 


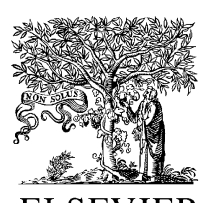

ELSEVIER

\title{
Gap filling strategies for defensible annual sums of net ecosystem exchange $\mathrm{e}^{\text {h }}$
}

\author{
Eva Falge ${ }^{\mathrm{a}, \mathrm{r}, *}$, Dennis Baldocchi ${ }^{\mathrm{a}}$, Richard Olson ${ }^{\mathrm{b}}$, Peter Anthoni ${ }^{\mathrm{c}}$, Marc Aubinet ${ }^{\mathrm{d}}$, \\ Christian Bernhofer ${ }^{\mathrm{e}}$, George Burba ${ }^{\mathrm{f}}$, Reinhart Ceulemans ${ }^{\mathrm{g}}$, Robert Clement ${ }^{\mathrm{h}}$, \\ Han Dolman ${ }^{\mathrm{i}}$, André Granier ${ }^{\mathrm{j}}$, Patrick Gross ${ }^{\mathrm{j}}$, Thomas Grünwald ${ }^{\mathrm{e}}$, David Hollinger ${ }^{\mathrm{k}}$, \\ Niels-Otto Jensen ${ }^{1}$, Gabriel Katul ${ }^{m}$, Petri Keronen ${ }^{n}$, Andrew Kowalski ${ }^{g}$, \\ Chun Ta Lai ${ }^{\mathrm{m}}$, Beverley E. Law ${ }^{\mathrm{c}}$, Tilden Meyers ${ }^{\mathrm{o}}$, John Moncrieff ${ }^{\mathrm{h}}$, Eddy Moors ${ }^{\mathrm{i}}$, \\ J. William Munger ${ }^{p}$, Kim Pilegaard ${ }^{\mathrm{l}}$, Üllar Rannik ${ }^{\mathrm{n}}$, Corinna Rebmann ${ }^{\mathrm{q}}$, \\ Andrew Suyker ${ }^{\mathrm{f}}$, John Tenhunen ${ }^{\mathrm{r}}$, Kevin Tu ${ }^{\mathrm{s}}$, Shashi Verma ${ }^{\mathrm{f}}$, Timo Vesala ${ }^{\mathrm{n}}$, \\ Kell Wilson ${ }^{\mathrm{o}}$, Steve Wofsy ${ }^{\mathrm{p}}$ \\ a SPM, University of California, Berkeley, Berkeley, CA 94704, USA \\ ${ }^{\mathrm{b}}$ Environmental Science Division, Oak Ridge National Laboratory, Oak Ridge, TN, USA \\ ${ }^{\mathrm{c}}$ Richardson Hall, Oregon State University, Corvallis, OR 97331-2209, USA \\ ${ }^{\mathrm{d}}$ Unité de Physique, Faculté des Sciences Agronomiques de Gembloux, B-50 30 Gembloux, Belgium \\ e Technische Universität Dresden, IHM Meteorologie, Pienner Str. 9, 01737 Tharandt, Germany \\ ${ }^{\mathrm{f}}$ School of Natural Resource Sciences, University of Nebraska-Lincoln, 244 L.W. Chase Hall, P.O. Box 830728, Lincoln, NE 68583-0728, USA \\ ${ }^{\mathrm{g}}$ Department of Biology, Laboratory of Plant Ecology, University of Antwerpen, Universiteitsplein 1, B-2610, Wilrijk, Antwerp, Belgium \\ ${ }^{\mathrm{h}}$ Institute of Ecology and Resource Management, University of Edinburgh, Edinburgh EH9 3JU, UK \\ ${ }^{i}$ Alterra, Postbus 47, 6700 AA Wageningen, The Netherlands \\ j INRA, Unité d'Ecophysiologie Forestière, F-54280 Champenoux, France \\ ${ }^{\mathrm{k}}$ USDA Forest Service, 271 Mast Rd, Durham, NH 03824, USA \\ ${ }^{1}$ Plant Biology and Biogeochemistry Department, Risoe National Laboratory, P.O. Box 49, DK-4000 Roskilde, Denmark \\ ${ }^{m}$ School of the Environment, Box 90328, Duke University, Durham, NC 27708-0328, USA \\ ${ }^{\mathrm{n}}$ Department of Physics, University of Helsinki, P.O. Box 9, FIN-00014 Helsinki, Finland \\ ${ }^{\circ}$ NOAA/ATDD, 456 S. Illinois Avenue, Oak Ridge, TN 37831-2456, USA \\ ${ }^{\mathrm{p}}$ Department of Earth and Planetary Sciences, Harvard University, 20 Oxford St., Cambridge, MA 02138, USA \\ ${ }^{\mathrm{q}}$ Max-Planck-Institut für Biogeochemie, Tatzendpromenade 1a, 07701 Jena, Germany \\ ${ }^{\mathrm{r}}$ Pflanzenökologie, Universität Bayreuth, 95440 Bayreuth, Germany \\ ${ }^{s}$ Department of Natural Resources, University of New Hampshire, Durham, NH 03824, USA
}

Received 17 March 2000; received in revised form 12 September 2000; accepted 21 September 2000

\footnotetext{
${ }^{2}$ Data provided by: EUROFLUX: Corinna Rebmann/E.-D. Schulze/John Tenhunen; Thomas Grünwald/Christian Bernhofer; E.J. Moors/Jan A. Elbers/Han Dolman; Kim Pilegaard/Niels-Otto Jensen; Marc Aubinet; Üllar Rannik/Timo Vesala; André Granier/Patrick Gross; Robert Clement/John Moncrieff; Andrew Kowalski/Reinhart Ceulemans. AmeriFlux: Dennis Baldocchi/Kell Wilson; David Hollinger; Bill Munger/Steve Wofsy; Tilden Meyers; Shashi Verma/Andrew Suyker/George Burba; Peter Anthoni/Beverly Law; Chun Ta Lai/Gabriel Katul/Ram Oren.

${ }^{*}$ Corresponding author. Tel.: +49-921-55-2576; fax: +49-921-55-2564.

E-mail address: falge@nature.berkeley.edu (E. Falge).
}

0168-1923/01/\$ - see front matter @ 2001 Elsevier Science B.V. All rights reserved.

PII: S 0168 - 1923(00)00225-2 


\section{Abstract}

Heightened awareness of global change issues within both science and political communities has increased interest in using the global network of eddy covariance flux towers to more fully understand the impacts of natural and anthropogenic phenomena on the global carbon balance. Comparisons of net ecosystem exchange $\left(F_{\mathrm{NEE}}\right)$ responses are being made among biome types, phenology patterns, and stress conditions. The comparisons are usually performed on annual sums of $F_{\mathrm{NEE}}$; however, the average data coverage during a year is only $65 \%$. Therefore, robust and consistent gap filling methods are required.

We review several methods of gap filling and apply them to data sets available from the EUROFLUX and AmeriFlux databases. The methods are based on mean diurnal variation (MDV), look-up tables (LookUp), and nonlinear regressions (Regr.), and the impact of different gap filling methods on the annual sum of $F_{\mathrm{NEE}}$ is investigated. The difference between annual $F_{\mathrm{NEE}}$ filled by MDV compared to $F_{\mathrm{NEE}}$ filled by Regr. ranged from -45 to $+200 \mathrm{~g} \mathrm{C} \mathrm{m}^{-2}$ per year (MDV-Regr.). Comparing LookUp and Regr. methods resulted in a difference (LookUp-Regr.) ranging from -30 to $+150 \mathrm{~g} \mathrm{C} \mathrm{m}^{-2} \mathrm{per}$ year.

We also investigated the impact of replacing measurements at night, when turbulent mixing is insufficient. The nighttime correction for low friction velocities $\left(u_{*}\right)$ shifted annual $F_{\mathrm{NEE}}$ on average by $+77 \mathrm{~g} \mathrm{C} \mathrm{m}^{-2}$ per year, but in certain cases as much as $+185 \mathrm{~g} \mathrm{C} \mathrm{m}^{-2}$ per year.

Our results emphasize the need to standardize gap filling-methods for improving the comparability of flux data products from regional and global flux networks. (C) 2001 Elsevier Science B.V. All rights reserved.

Keywords: FLUXNET; EUROFLUX; AmeriFlux; Eddy covariance; $F_{\mathrm{NEE}}$; Data filling; Interpolation techniques

\section{Introduction}

Contemporary investigators are able to apply the eddy covariance technique to acquire nearly continuous measurements of carbon exchange between the atmosphere and biosphere. The regional collections of eddy covariance flux towers were formalized into the EUROFLUX and AmeriFlux networks in 1996. Although some towers have been in operation for many years, this was the start of a flux community effort to collect continuous measurements of ecosystem carbon and energy exchange to understand the controls on carbon fluxes. Inter-comparisons of carbon and energy fluxes across natural and managed ecosystems and climatic gradients within each regional network (Valentini et al., 2000; Hollinger et al., 2000) assess the processes controlling these fluxes, and inter- and intra-annual variability (e.g. Goulden et al., 1996a; Chen et al., 1999).

In 1997, the FLUXNET project was established to compile the long-term measurements of carbon dioxide, water vapor, and energy exchange from the regional networks into consistent, quality assured, documented data sets for a variety of worldwide ecosystems (Baldocchi et al., 1996; Running et al., 1999). The increasing amount of ecosystem carbon and energy exchange data presents new challenges to FLUXNET, the global umbrella, to provide qualified flux data to policy makers dealing with global change issues, and modelers interested in regional scaling or validation of soil-vegetation-atmosphere transfer (SVAT) models and biogeochemical cycling models (Running et al., 1999). These users have identified the need to have estimates of net ecosystem exchange $\left(F_{\mathrm{NEE}}\right)$ from a variety of ecosystems for monthly and annual time periods. With the launching of the NASA Terra satellite, flux tower data soon will be applied on even larger scales, for validations of these remotely sensed products.

Data from eddy covariance are usually reported half-hourly with the objective to collect data $24 \mathrm{~h}$ a day and 365 days a year. However, the average data coverage during a year is only $65 \%$ due to system failures or data rejection. Therefore, gap-filling procedures need to be established for providing complete data sets. Standardization of the procedure will allow defensible fillings and the creation of comparable data sets, which form the basis for inter-site comparisons. The purpose of this paper is to review filling methodologies that will produce comparable results, and give some perspectives on common problems observed in eddy covariance data. 


\begin{tabular}{|c|c|}
\hline \multicolumn{2}{|c|}{ Nomenclature } \\
\hline \multicolumn{2}{|c|}{ Meteorological variables } \\
\hline$P_{\mathrm{a}}$ & barometric pressure $(\mathrm{kPa})$ \\
\hline$Q_{\mathrm{PPFD}}$ & $\begin{array}{l}\text { photosynthetic photon flux density } \\
\left(\mu \mathrm{mol} \mathrm{m}-2 \mathrm{~s}^{-1}\right)\end{array}$ \\
\hline$R_{\mathrm{g}}$ & global radiation $\left(\mathrm{W} \mathrm{m}^{-2}\right)$ \\
\hline $\mathrm{RH}$ & relative humidity (\%) \\
\hline$R_{\mathrm{n}}$ & net radiation $\left(\mathrm{W} \mathrm{m}^{-2}\right)$ \\
\hline$T_{\mathrm{a}}$ & air temperature $\left({ }^{\circ} \mathrm{C}\right)$ \\
\hline$T_{\mathrm{s}}$ & soil temperature $\left({ }^{\circ} \mathrm{C}\right)$ \\
\hline$u$ & wind speed $\left(\mathrm{m} \mathrm{s}^{-1}\right)$ \\
\hline & friction velocity $\left(\mathrm{m} \mathrm{s}^{-1}\right)$ \\
\hline VPD & vapor pressure deficit $(\mathrm{kPa})$ \\
\hline \multicolumn{2}{|c|}{ Flux variables } \\
\hline$F_{\mathrm{GPP}}$ & $\begin{array}{l}\text { gross primary production } \\
\left(F_{\mathrm{GPP}}=F_{\mathrm{RA}}+F_{\mathrm{NPP}}\right. \\
=F_{\mathrm{RA}}+F_{\mathrm{RH}}+F_{\mathrm{NEP}} \\
=F_{\mathrm{RE}}+F_{\mathrm{NEP}} \\
\left.=F_{\mathrm{RE}}-F_{\mathrm{NEE}}\right)\left(\mathrm{g} \mathrm{C} \mathrm{m}^{-2} \text { per year }\right)\end{array}$ \\
\hline$F_{\mathrm{GPP}, \mathrm{opt}}$ & $\begin{array}{l}F_{\mathrm{GPP}} \text { at optimum light } \\
\left(\text { e.g. } Q_{\mathrm{PPFD}}=2000 \mu \mathrm{mol} \mathrm{m}^{-2} \mathrm{~s}^{-1}\right) \\
\left(\mu \mathrm{mol} \mathrm{CO} \mathrm{m}_{2} \mathrm{~m}^{-2} \mathrm{~s}^{-1}\right)\end{array}$ \\
\hline$F_{\mathrm{GPP}, \text { Tref }}$ & $\begin{array}{l}F_{\mathrm{GPP}} \text { at optimum light and } T_{\text {ref }} \\
\left(\mu \mathrm{mol} \mathrm{CO}_{2} \mathrm{~m}^{-2} \mathrm{~s}^{-1}\right)\end{array}$ \\
\hline$F_{\mathrm{GPP}, \text { sat }}$ & $\begin{array}{l}F_{\mathrm{GPP}} \text { at saturating light } \\
\left(\mu \mathrm{mol} \mathrm{CO} \mathrm{m}^{-2} \mathrm{~s}^{-1}\right)\end{array}$ \\
\hline$F_{\mathrm{NEE}}$ & $\begin{array}{l}\text { net ecosystem exchange of } \mathrm{CO}_{2} \text {, } \\
\text { calculated as the sum of the } \mathrm{CO}_{2} \\
\text { flux determined by eddy covariance } \\
\text { and the } \mathrm{CO}_{2} \text { storage change in the } \\
\text { canopy air layer (the sign convention } \\
\text { of } F_{\mathrm{NEE}} \text { is from the perspective of } \\
\text { the atmosphere, i.e. a negative sign } \\
\text { means the atmosphere is losing } \\
\text { carbon) ( } \mu \text { mol } \mathrm{CO}_{2} \mathrm{~m}^{-2} \mathrm{~s}^{-1} \text { or } \\
\mathrm{g} \mathrm{C} \mathrm{m}^{-2} \text { per year) }\end{array}$ \\
\hline$F_{\mathrm{NEP}}$ & $\begin{array}{l}\text { net ecosystem production } \\
\left(\mathrm{g} \mathrm{C} \mathrm{m}^{-2} \text { per year }\right)\end{array}$ \\
\hline & $\begin{array}{l}\text { net primary production } \\
\left(\mathrm{g} \mathrm{C} \mathrm{m}^{-2} \text { per year }\right)\end{array}$ \\
\hline & $\begin{array}{l}\text { autotrophic respiration } \\
\left(\mathrm{g} \mathrm{C} \mathrm{m}^{-2} \text { per year }\right)\end{array}$ \\
\hline$F_{\mathrm{RE}}$ & $\begin{array}{l}\text { ecosystem respiration } \\
\left(\mu \mathrm{mol} \mathrm{CO}_{2} \mathrm{~m}^{-2} \mathrm{~s}^{-1} \text { or }\right. \\
\left.\mathrm{g} \mathrm{C} \mathrm{m}^{-2} \text { per year }\right)\end{array}$ \\
\hline
\end{tabular}

\begin{tabular}{|c|c|}
\hline$F_{\mathrm{RE}, 283}$ & $\begin{array}{l}F_{\mathrm{RE}} \text { at a reference temperature } \\
\text { of } 283 \mathrm{~K}\left(\mu \mathrm{mol} \mathrm{CO} \mathrm{m}^{-2} \mathrm{~s}^{-1}\right)\end{array}$ \\
\hline$F_{\mathrm{RE}, \mathrm{day}}$ & $\begin{array}{l}\text { ecosystem respiration during daytime } \\
\left(\mu \mathrm{mol} \mathrm{CO} \mathrm{C}_{2} \mathrm{~m}^{-2} \mathrm{~s}^{-1}\right)\end{array}$ \\
\hline$F_{\text {RE, night }}$ & $\begin{array}{l}\text { ecosystem respiration during nighttime } \\
\left(\mu \mathrm{mol} \mathrm{CO} \mathrm{m}^{-2} \mathrm{~s}^{-1}\right)\end{array}$ \\
\hline$F_{\mathrm{RE}, \mathrm{Tref}}$ & $\begin{array}{l}F_{\mathrm{RE}} \text { at reference temperature } T_{\text {ref }} \\
\left(\mu \mathrm{mol} \mathrm{CO}_{2} \mathrm{~m}^{-2} \mathrm{~s}^{-1}\right)\end{array}$ \\
\hline$F_{\mathrm{RH}}$ & $\begin{array}{l}\text { heterotrophic respiration } \\
\left(\mathrm{g} \mathrm{C} \mathrm{m}^{-2} \text { per year) }\right.\end{array}$ \\
\hline \multicolumn{2}{|c|}{ Other variables } \\
\hline$a^{\prime}$ & $\begin{array}{l}\text { ecosystem quantum yield } \\
\left(\mu \mathrm{mol} \mathrm{CO}_{2} \mathrm{~m}^{-2} \mathrm{~s}^{-1}\right. \\
\left.\left(\mu \text { mol quantum } \mathrm{m}^{-2} \mathrm{~s}^{-1}\right)^{-1}\right)\end{array}$ \\
\hline$A$ & $\begin{array}{l}\text { parameter of Van't Hoff equation } \\
\text { (see Appendix A) }\left(\mu \mathrm{mol} \mathrm{CO} \mathrm{CO}_{2} \mathrm{~m}^{-2} \mathrm{~s}^{-1}\right)\end{array}$ \\
\hline$B$ & $\begin{array}{l}\text { parameter of Van't Hoff equation } \\
\text { (see Appendix A) }\left({ }^{\circ} \mathrm{C}\right)^{-1}\end{array}$ \\
\hline$d$ & number of days per year \\
\hline$E_{0}$ & $\begin{array}{l}\text { parameter of Lloyd \& Taylor equation } \\
\text { (see Appendix A) (K) }\end{array}$ \\
\hline$E_{\mathrm{a}}$ & $\begin{array}{l}\text { parameter of Arrhenius equation } \\
\text { (see Appendix A) }\left(\mathrm{J} \mathrm{mol}^{-1}\right)\end{array}$ \\
\hline$h$ & index for the half-hour $(h=1, \ldots 48)$ \\
\hline$\Delta H_{\mathrm{a}}$ & $\begin{array}{l}\text { parameter of Johnson equation } \\
\text { (see Appendix A) }\left(\mathrm{J} \mathrm{mol}^{-1}\right)\end{array}$ \\
\hline$\Delta H_{\mathrm{d}}$ & $\begin{array}{l}\text { parameter of Johnson equation } \\
\text { (see Appendix A) }\left(\mathrm{J} \mathrm{mol}^{-1}\right)\end{array}$ \\
\hline$i$ & $\begin{array}{l}\text { index for averaging window, } \\
i=1, \ldots \text { integer }(d / n)+1\end{array}$ \\
\hline$n$ & window size (days) \\
\hline$R$ & gas constant $\left(8.134 \mathrm{~J} \mathrm{~K}^{-1} \mathrm{~mol}^{-1}\right)$ \\
\hline$\Delta S$ & $\begin{array}{l}\text { parameter of Johnson equation } \\
\text { (see Appendix A) }\left(\mathrm{J} \mathrm{K}^{-1} \mathrm{~mol}^{-1}\right)\end{array}$ \\
\hline$T$ & temperature $\left({ }^{\circ} \mathrm{C}\right)$ \\
\hline$T_{0}$ & $\begin{array}{l}\text { parameter of Lloyd \& Taylor equation } \\
\text { (see Appendix A) (K) }\end{array}$ \\
\hline$T_{\mathrm{K}}$ & air or soil temperature $(\mathrm{K})$ \\
\hline$T_{\text {ref }}$ & $\begin{array}{l}\text { reference temperature (air or soil) } \\
(298.16 \text { or } 283.16 \mathrm{~K})\end{array}$ \\
\hline $\bar{X}_{h, i}$ & $\begin{array}{l}\text { array of length } i \text { and width } h \text {, containing } \\
\text { bin-averages of data for the respective } \\
\text { half-hour and data window } \\
\text { (same as data) }\end{array}$ \\
\hline$\sigma_{w}$ & $\begin{array}{l}\text { standard deviation of } w \text {, the vertical } \\
\text { wind component }\left(\mathrm{m} \mathrm{s}^{-1}\right)\end{array}$ \\
\hline
\end{tabular}


The most appropriate gap filling method may be influenced by the unique conditions at a flux tower site and the end use of the flux data. For example, users with interest in annual averages will choose different methodologies than those preparing complete half-hourly data sets for SVAT model validation. If missing or rejected values in a half-hourly data set would be perfectly random distributed, the calculation of an annual sum could be easily performed, i.e. by taking the average of all available data, and converting the unit of the average to the appropriate unit per year (for $F_{\mathrm{NEE}}$, e.g. converting $\mu \mathrm{mol} \mathrm{m}^{-2} \mathrm{~s}^{-1}$ to $\mathrm{g} \mathrm{C} \mathrm{m}^{-2}$ per year). Data gaps, however, do not occur randomly because of system failures or rejection of poor data. The non-randomness of the gaps in the data leads to the need to develop and test a variety of gap-filling methods.

At present the flux measurement community has agreed on common measurement techniques (open or closed path infrared gas analyzer, 3-D sonic anemometer) and data processing routines (e.g. McMillen, 1988, or Moncrieff et al., 1997). No universal method has emerged for filling of missing or rejected data. Some investigators have used diurnal variations (hourly averages binned over periods of 15 days) to estimate annual and seasonal sums of $F_{\mathrm{NEE}}$ for forests (Greco and Baldocchi, 1996; Jarvis et al., 1997). Others have applied variations of light response functions (Goulden et al., 1996b; Granier et al., 2000; Pilegaard et al., 2000; Grünwald and Bernhofer, 2000). Aubinet et al. (2000) report several different techniques, including neural networks, being applied in filling $F_{\mathrm{NEE}}$ data sets. As more inter-site comparisons of fluxes and annual sums are planned, the effects of applying different filling strategies on the comparability of the results need to be established.

Because no standard filling methodology exists, this work investigates the performance of selected gap-filling methods and their effects on the annual sum of $F_{\text {NEE }}$ for 28 data sets from the AmeriFlux and EUROFLUX networks (Table 1). The three major filling methodologies investigated in this paper are mean diurnal variation "MDV" of prescribed periods, look-up tables "LookUp" and nonlinear regression "Regr.". LookUp and Regr. will be also referred to as semi-empirical methods. Since major offsets in the annual sum might occur due to a correction for flux under-estimation during night $\left(u_{*}\right.$-correction, e.g. Aubinet et al., 2000), we examine the effects of gap-filling procedures on both $u_{*}$-corrected, and not $u_{*}$-corrected data sets.

We applied several variations of the three major groups, and tested the performance of the methods in an analysis of the errors introduced when filling artificial gaps in data from four sites, selected to represent four functional types: conifers, deciduous forests, crops, and grassland.

\section{An overview of data preparation, filling methods and their sensitivities}

\subsection{Data basis}

Flux measurements were obtained for nine EUROFLUX sites for 1997 and 10 AmeriFlux sites with 1-2 years of data collected between 1992 and 1999 resulting in a total of 28 unique site-year combinations (Table 1). Although each data contributor had reviewed their data in relation to their analysis needs, we required additional processing to prepare the data for our analysis (Foken and Wichura, 1995; Mahrt, 1998).

To investigate the overall effect of filling routines on any given data set of $F_{\mathrm{NEE}}$, we decided to perform the filling on both the original data, if available, and $u_{*}$-corrected data. The $u_{*}$-correction per se is not entirely accepted in the research community. Rationale for criticizing the approach results from both end-use specifications and methodological difficulties. $\mathrm{CO}_{2}$ fluxes are affected by biological processes in soil and vegetation and physical processes in the canopy air space. Effects of physical processes have to be eliminated, if eddy covariance data are interpreted as "biological" fluxes, i.e. as balance of assimilatory and respiratory fluxes from all ecosystem components. Then, the correction for storage effects and eventually missed $\mathrm{CO}_{2}$-exchange under low $u_{*}$ conditions becomes necessary. However, methods accounting for lost exchange during calm conditions often suffer from the low coefficient of determination that is computed, when regressing $\mathrm{CO}_{2}$-exchange normalized for temperature on friction velocity $\left(u_{*}\right)$. Often, $r^{2}<0.3$, so it is questionable whether one should correct flux densities with an uncertain correction algorithm. Statistical uncertainty is further ampli- 
Table 1

Site information for 18 sites from the EUROFLUX and AmeriFlux projects and several years

\begin{tabular}{|c|c|c|c|c|c|c|}
\hline Site & State (country) & Period & Abbreviations & Coordinates & Species & Data providers \\
\hline \multicolumn{7}{|l|}{ EUROFLUX } \\
\hline WeidenBrunnen & Germany & 1997 & WE97 & $50^{\circ} 09^{\prime} \mathrm{N} 11^{\circ} 52^{\prime} \mathrm{E}$ & Norway Spruce & $\begin{array}{l}\text { Corinna Rebmann/E.-D. } \\
\text { Schulze/John Tenhunen }\end{array}$ \\
\hline Tharandt & Germany & 1997 & TH97 & $50^{\circ} 58^{\prime} \mathrm{N} 13^{\circ} 40^{\prime} \mathrm{E}$ & Norway Spruce & $\begin{array}{l}\text { Thomas Grünwald/Christian } \\
\text { Bernhofer }\end{array}$ \\
\hline Vielsalm & Belgium & 1997 & VI97 & $50^{\circ} 18^{\prime} \mathrm{N} 6^{\circ} 0^{\prime} \mathrm{E}$ & European Beech & Marc Aubinet \\
\hline Loobos & Netherlands & 1997 & LO97 & $52^{\circ} 10^{\prime} \mathrm{N} 5^{\circ} 44^{\prime} 38^{\prime \prime} \mathrm{E}$ & Scots Pine & Eddy Moors/Han Dolman \\
\hline Soroe & Denmark & 1997 & SO97 & $55^{\circ} 29^{\prime} 13^{\prime \prime} \mathrm{N} 11^{\circ} 38^{\prime} 45^{\prime \prime} \mathrm{E}$ & European Beech & Kim Pilegaard/Niels-Otto Jensen \\
\hline Hyytiala & Finland & 1997 & HY97 & $61^{\circ} 51^{\prime} \mathrm{N} 24^{\circ} 17^{\prime} \mathrm{E}$ & Scots Pine & Ullar Rannik/Timo Vesala \\
\hline Hesse & France & 1997 & HE97 & $48^{\circ} 40^{\prime} \mathrm{N} 7^{\circ} 50^{\prime} \mathrm{E}$ & European Beech & André Granier \\
\hline Brasschaat & Belgium & 1997 & BR97 & $51^{\circ} 18^{\prime} \mathrm{N} 4^{\circ} 31^{\prime} \mathrm{E}$ & Scots Pine, Oaks & $\begin{array}{l}\text { Andrew Kowalski/N. } \\
\text { Shurpali/Reinhart Ceulemans }\end{array}$ \\
\hline Aberfeldy & UK & 1997 & AB97 & $56^{\circ} 37^{\prime} \mathrm{N} 3^{\circ} 48^{\prime} \mathrm{W}$ & Sitka Spruce & Robert Clement/John Moncrieff \\
\hline \multicolumn{7}{|l|}{ AmeriFlux } \\
\hline WalkerBranch & TN (USA) & 1995-1997 & WB95, WB96, WB97 & $35^{\circ} 57^{\prime} 30^{\prime \prime} \mathrm{N} 84^{\circ} 17^{\prime} 15^{\prime \prime} \mathrm{W}$ & Oak-Hickory & Dennis Baldocchi/Kell Wilson \\
\hline Howland & ME (USA) & 1996 & HL96 & $45^{\circ} 15^{\prime} \mathrm{N} 68^{\circ} 45^{\prime} \mathrm{W}$ & Spruce-Hemlock & David Hollinger \\
\hline Harvard & MA (USA) & 1992-1996 & $\begin{array}{l}\text { HV92, HV93, } \\
\text { HV94, } \\
\text { HV95, HV96 }\end{array}$ & $42^{\circ} 32^{\prime} \mathrm{N} 72^{\circ} 11^{\prime} \mathrm{W}$ & Oak-Maple & J. William Munger/Steve Wofsy \\
\hline LittleWashita & OK (USA) & 1997, 1998 & LW97, LW98 & $34^{\circ} 57^{\prime} 37^{\prime \prime} \mathrm{N} 97^{\circ} 58^{\prime} 42^{\prime \prime} \mathrm{W}$ & Rangeland & Tilden Meyers \\
\hline Bondville & IL (USA) & 1997 & BV97 & $40^{\circ} 0^{\prime} 22^{\prime \prime} \mathrm{N} 88^{\circ} 17^{\prime} 31^{\prime \prime} \mathrm{W}$ & Corn & Tilden Meyers \\
\hline Bondville & IL (USA) & 1998 & BV98 & $40^{\circ} 0^{\prime} 22^{\prime \prime} \mathrm{N} 88^{\circ} 17^{\prime} 31^{\prime \prime} \mathrm{W}$ & Soybean & Tilden Meyers \\
\hline Shidler & OK (USA) & $15 / 9 / 96-14 / 9 / 97$ & SH97 & $36^{\circ} 51^{\prime} \mathrm{N} 96^{\circ} 41^{\prime} \mathrm{W}$ & Tallgrass Prairie & Shashi Verma \\
\hline Ponca & OK (USA) & $21 / 8 / 96-20 / 8 / 97$ & PO97 & $36^{\circ} 45^{\prime} \mathrm{N} 97^{\circ} 05^{\prime} \mathrm{W}$ & Wheat & Shashi Verma \\
\hline Metolius & OR (USA) & 1996, 1997 & ME96, ME97 & $44^{\circ} 29^{\prime} 56^{\prime \prime} \mathrm{N} 121^{\circ} 37^{\prime} 26^{\prime \prime} \mathrm{W}$ & Ponderosa Pine & Peter Anthony/Beverley E. Law \\
\hline Duke Forest & NC (USA) & 1998, 1999 & DU98, DU99 & $35^{\circ} 52^{\prime} \mathrm{N} 79^{\circ} 59^{\prime} \mathrm{W}$ & Loblolly Pine & Chun Ta Lai/Gabriel Katul/Ram Oren \\
\hline
\end{tabular}


fied, because $\mathrm{CO}_{2}$-exchange and friction velocity are auto-correlated. The routine we applied for all sites is described in the Appendix A.

\subsection{Filling using redundant variables}

Some gaps in meteorological variables were filled using redundant measures. For instance, gaps in $Q_{\text {PPFD }}$ were filled via the site-specific overall ratio between $R_{\mathrm{g}}$ and $Q_{\mathrm{PPFD}}$, and actual $R_{\mathrm{g}}$. In addition, the ratio was used to perform a consistency test between radiation measurements, as an indication of calibration or unit problems. Potential radiation on top of the atmosphere also sets an overall upper limit for radiation measurements. Standard relationships between VPD, $T_{\mathrm{a}}$, RH, or $u_{*}$, momentum $\left(\tau\right.$ in $\mathrm{kg} \mathrm{m}^{-1} \mathrm{~s}^{-2}$ ), $T_{\mathrm{a}}$ and $P_{\mathrm{a}}$ were used to check that the mathematical calculations were correct.

Linear interpolation between the values adjacent to the missing value(s) is often being used for small gaps (2-3 half-hourly means missing), and is especially useful to replace missing values in meteorological variables, such as temperature or relative humidity. It was included here as an optional data set pre-treatment before filling larger gaps. Another optional data pre-treatment was merging the half-hourly time step to hours, i.e. the resulting hourly value was calculated as average of the two half-hourly values if available, or set to the measured half-hourly value, if only one was available.

\subsection{Filling methods}

Gap filling methods applied here include mean diurnal variation of previous periods, look-up tables for $F_{\text {NEE }}$ during assorted meteorological conditions (e.g. Jarvis et al., 1976), and gap filling by nonlinear regressions (e.g. in Goulden et al., 1996b; Jarvis et al., 1997; Aubinet et al., 2000; Granier et al., 2000; Pilegaard et al., 2000). In principle, these methods are only able to reproduce mean flux densities or meteorological conditions. They cannot reproduce deviations from means in any meaningful and statistically defensible manner.

Another critical issue is whether the available data used to construct the mean diurnal variation or regression equation is an unbiased sample of conditions. If the gaps are biased towards a particular condition the resulting fit or mean diurnal variation will not be representative for the conditions in the gap. In this case, process-oriented ecosystem gas exchange models, parameterized from independent data sets, should replace simple gap filling routines.

We know from Jensen's inequality (Ruel and Ayres, 1999), that the expected value of a non-linear function with a non-zero variance does not equal the function evaluated using the mean of the forcing variable. Non-linearity, however, is a common feature in biology, with the most familiar examples being saturated light response of photosynthesis and temperature response of respiration, as well as midday depression of gas exchange, endogenous diurnal rhythms, or seasonal adaptations and drought effects. Consequently, gap-filling methods will be applied to subsets of data constructed to minimize variances in both, data and potential driving forces. The question which part of the variance should be minimized, is the reason we examine several techniques.

The mean diurnal approach has the potential to capture non-linearity due to diurnal, or temporal changes in response. It captures interactions between light and temperature in a simple manner, as they show a lagged co-variance over the course of the day. It also does not rely on a preconceived notion about functional responses between fluxes and forcing variables. On the other hand, the functional responses between fluxes and meteorological variables usually observed in the data may not be achieved for values filled by mean diurnal variations, and the method has potential to be biased on extremely clear or cloudy days.

By defining "adequate" mathematical equations for non-linear regression or selecting appropriate sorting variables for look-up table classes these methods capture and preserve the response between fluxes and meteorological driving forces. To describe seasonality or effects due to diurnal patterns separate time periods can be addressed, but are constrained by sufficient data coverage of the resulting classes.

In the following sections we describe the gap filling methods in more detail.

\subsubsection{Mean diurnal variation}

In this method, a missing observation is replaced by the mean for that time period (half-hour) based on adjacent days. The methods for derivation of mean 
diurnal pattern of bin-averaged (half-) hourly measurements differ mainly in the length of the time interval of averaging (window size, usually 4-15 days). Four days often were not enough to determine a mean from measurements. In addition, recent work on spectral analysis of flux data showed a spectral peak at 3-4 days, clear evidence not to use this period for averaging (Baldocchi et al., 2000b). Data windows of days 7 and 14 were chosen for averaging in the application here. Larger window sizes were not considered for carbon fluxes, as nonlinear dependence on environmental variables introduces errors through averaging (see Section 1). In addition to the two interval lengths, two different algorithms were implemented, (a) an "independent" window, and (b) a "gliding" window (see Appendix A, Eqs. (A.1) and (A.2)). In (a) for each subsequent period of data (where the period length is defined by the window size) mean diurnal variations were established to fill gaps within that period. In (b) a window of prescribed size around each gap is used to construct mean diurnal variation for gap filling within that window. If only seasonal and annual sums are of interest this method is equivalent to summing the data over multi-day bins with each (half-) hour of the day averaged separately.

\subsubsection{Semi-empirical methods}

Semi-empirical gap filling preserves the response to temperature and photosynthetic photon flux density - as found in the data. Responses are described by average values for assorted environmental conditions (look-up tables) or applying a nonlinear regression. Look-up table methods allow for variable response, i.e. the shape of a light response can vary between linear and rectangular-hyperbolic, based on the data analyzed compared to nonlinear regressions, which prescribe the shape of the response function. As an alternative, gaps in $F_{\mathrm{NEE}}$ are filled applying saturation functions for the light response, optimum curves for the temperature response of light-saturated capacities, and different exponential functions for nighttime fluxes.

2.3.2.1. Look-up tables. Tables were created for each site so that missing values of $F_{\mathrm{NEE}}$ could be "looked-up" based on the environmental conditions associated with the missing data. Tables were created to represent changing environmental conditions based on either six bimonthly periods or four seasonal periods. Seasons were assigned as periods ranging from 1 April to 31 May, 1 June to 30 September, 1 October to 30 November, and 1 December to 31 March. For look-up tables average $F_{\mathrm{NEE}}$ was compiled for a maximum of six (or four) seasonal periods $\times 23$ $Q_{\mathrm{PPFD}}$-classes $\times 35 T_{\mathrm{a}}$-classes. $Q_{\mathrm{PPFD}}$-classes consisted of $100 \mu \mathrm{mol} \mathrm{m}{ }^{-2} \mathrm{~s}^{-1}$ intervals from 0 to 2200 with a separate class for $Q_{\mathrm{PPFD}}=0$. Similarly, $T_{\mathrm{a}}$-classes were defined through $2^{\circ} \mathrm{C}$ intervals ranging from $-19^{\circ} \mathrm{C}$ to $49^{\circ} \mathrm{C}$. The procedure produced tables of $F_{\text {NEE }}$ means and standard deviations for each class. Gaps in the look-up tables (classes with no mean assigned) were interpolated linearly, the maximum gap width spanned was $300 \mu \mathrm{mol} \mathrm{m}^{-2} \mathrm{~s}^{-1}$ for a light curve at a given temperature, and $6^{\circ} \mathrm{C}$ within a temperature curve at a given light level.

Although we are evaluating filling methods to be applied uniformly to a variety of sites, experience with the semi-empirical methods that use $Q_{\text {PPFD }}$ data illustrate the need to consider unique site conditions. As shown in numerous examples in the literature (e.g. Goulden et al., 1996b; Greco and Baldocchi, 1996; Valentini et al., 1996; Clark et al., 1999; Pilegaard et al., 2000; Granier et al., 2000), the light response curves for seasonal periods or a given temperature interval apparently show high scatter. High scatter in the data is expected and depends on additional factors, as effects of daytime, seasonality of leaf, bole, soil physiology, water availability, or inhomogeneity in fetch/footprint area of the tower site. On the other hand, scatter in the canopy $\mathrm{CO}_{2}$-exchange light response curve can arise from the effects of cloud cover (Hollinger et al., 1994; Baldocchi, 1997; Gu et al., 2000). To reduce the residual scatter for individual sites consideration of additional factors might become necessary, for instance for sites with known drought effects. We did not include other factors in the analysis, as not all data at hand had information on soil water status, and the paper focuses on the investigation of the effects by commonly used filling strategies.

2.3.2.2. Nonlinear regression methods. In this method, regression relationships were established between $F_{\text {NEE }}$ components and associated controlling factors for each site and period of the year. The re- 
sulting equations were used to fill in missing $F_{\mathrm{NEE}}$ based on data for controlling factors during the period of missing $F_{\mathrm{NEE}}$. Daytime and nighttime data were addressed separately and time periods were defined as in 2.3.2.1 for either six bimonthly periods or four seasonal periods.

For nighttime data different temperature response functions were tested: Lloyd \& Taylor, Arrhenius, or Van't Hoff (Lloyd and Taylor, 1994, their Eqs. (4), (8), and (11); see also Appendix A, Eqs. (A.3)-(A.5)). For each period (six bimonthly or four seasonal periods) parameterizations were derived, resulting in a nighttime respiration term $\left(F_{\mathrm{RE}, \text { night }}\right)$, that combines leaf, bole and soil respiration. A concern in the analysis of the respiration data is that clear separation of the different respiration sources (leaves, bole, and soil) is not possible without independent measurements. The contribution of these sources will change over time, and in response to different developmental factors (e.g. air, soil, and bole temperature, soil water potential, etc.; Law et al., 1999b). Restricted by the overall availability of these factors, we decided including only responses to air or soil temperature in the analysis.

For filling daytime gaps, many different light response functions were tested (including linear, parabolic and hyperbolic functions). We selected either the Michaelis-Menten, or Misterlich functions (Michaelis and Menten, 1913, and Dagnelie, 1991; see also Appendix A, Eqs. (A.7)-(A.10)), because residual analysis showed better overall performance. Parameters were determined using three different approaches: (a) pooled for all temperatures of a given period, (b) a priori sub-sorted into $4{ }^{\circ} \mathrm{C}$ temperature classes, and (c) a combined determination of parameters describing light, and temperature response.

The combined determination of parameters used Eqs. (A.3), (A.6), and (A.10) from Appendix A. However, in this case the nonlinear problem could only be resolved by setting constraints, e.g. some parameters were held constant or estimated start values were used. As nonlinear regression computations are an iterative procedure, the routine must start with estimated values for each variable. The result of the algorithm would be independent of these initial guesses, as long as the data clearly define the assumed function. Eddy covariance data, however, has a lot of natural scatter, and often the data selection (by season, etc.) does not cover a sufficient range. In this application, $a^{\prime}$ as the slope of a linear regression of a light-response curve of $F_{\mathrm{NEE}}$ for low light intensities $\left(<400 \mu \mathrm{mol} \mathrm{m}^{-2} \mathrm{~s}^{-1}\right)$ was estimated a priori and pooling all temperature classes. Determination of $a^{\prime}$ together with the other parameters, but sorted in temperature classes, results in a weak (optimum) response of $a^{\prime}$ to temperature. This might be a real effect, as Ehleringer and Björkman (1977) showed that leaf quantum yield is temperature dependent. Here, however, $a^{\prime}$ is an operationally determined parameter based on stand gas exchange data, which might include changing ratios between system assimilation and respiration, or varying light transmission over the course of the day and season. So for suitability, we refrained from including a temperature effect on $a^{\prime}$.

Differences in filling results are expected from the assignment of seasonal periods, i.e. periods where responses are assumed to be constant. In some cases consideration of additional meteorological factors (as vapor pressure deficit, or drought), and human activities (as mowing of rangeland or harvesting of crops) might help improving the results.

\subsection{Error assessment}

To assess the applicability of a standard data filling method at various sites, we examined the potential bias error associated with each method. Mean error, standard deviation of the mean, skewness, and kurtosis were used to rate the different methods. The error addressed here is the error introduced by data pre-treating and filling methods only. For uncertainties of the data itself, such as that introduced by the eddy covariance method one should consult Moncrieff et al. (1996) and Goulden et al. (1996b).

As the filling procedures involve a considerable amount of computation time, we restricted the sensitivity analysis in this presentation to four sets of data (a Finnish conifer forest, HY97, a temperate deciduous forest, HV96, an agricultural crop, BV97, and a native grassland ecosystem, SH97). These data sets were chosen to represent a breadth of classes. They had the lowest percentage of original gaps in $F_{\mathrm{NEE}}$ data within their functional class (see Table 2).

Five artificial data sets were created, containing 25 , $35,45,55$, and $65 \%$ of gaps. Starting from the original gap percentage, artificial gaps were created separately for day and night, until the data set contained 
Table 2

Percentages of $F_{\mathrm{NEE}}$ (net ecosystem exchange) data, that were missing or had to be rejected for 18 sites from the EUROFLUX and AmeriFlux projects and several years ${ }^{\mathrm{a}}$

\begin{tabular}{lrrr}
\hline Site & \multicolumn{3}{c}{$F_{\text {NEE }}$ gap percentage } \\
\cline { 2 - 4 } & Day & Total & Night \\
\hline WE97 & 58.3 & 59.6 & 60.9 \\
TH97 & 33.4 & 37.8 & 42.3 \\
VI97 & 30.3 & 48.8 & 67.5 \\
LO97 & 35.4 & 35.6 & 35.9 \\
SO97 & 7.9 & 8.6 & 9.3 \\
HY97 & 27.2 & 24.7 & 22.2 \\
HE97 & 9.3 & 10.9 & 12.6 \\
BR97 & 63.9 & 65.1 & 66.2 \\
AB97 & 25.9 & 26.6 & 27.4 \\
WB95 & 33.9 & 41.5 & 49.1 \\
WB96 & 35.3 & 42.8 & 50.5 \\
WB97 & 38.3 & 46.4 & 54.6 \\
HL96 & 47.1 & 45.2 & 43.2 \\
HV92 & 43.8 & 39.7 & 35.6 \\
HV93 & 47.0 & 45.6 & 44.1 \\
HV94 & 21.7 & 19.0 & 16.3 \\
HV95 & 25.4 & 24.9 & 24.5 \\
HV96 & 19.1 & 17.8 & 16.4 \\
LW97 & 17.3 & 19.7 & 22.2 \\
LW98 & 22.8 & 24.4 & 26.0 \\
BV97 & 18.2 & 21.5 & 24.8 \\
BV98 & 22.7 & 27.2 & 31.8 \\
SH97 & 23.7 & 26.5 & 29.4 \\
PO97 & 40.1 & 39.7 & 39.3 \\
ME96 & 24.1 & 29.8 & 35.5 \\
ME97 & 40.5 & 43.3 & 46.2 \\
DU98 & 59.8 & 59.5 & 59.2 \\
DU99 & 40.7 & 41.7 & 42.6 \\
\hline
\end{tabular}

${ }^{a}$ The average for all sites is $32.6 \%$ during daytime, $37.0 \%$ during nighttime, and $34.8 \%$ total. For site abbreviations see Table 1 .

a given percentage of gaps for both day- and nighttime. For this analysis, potential biases introduced by a non-random distribution of original gaps were not considered, e.g. "simulating" longer gap-periods due to system break down or other problems. After introducing artificial gaps for each of the five data sets the respective gap filling methods were parameterized with the remaining data, and applied to fill the artificial data sets.

The absolute error for each method was calculated as the measured minus the computed value for each of the artificial gaps. For daytime carbon uptake, a positive error therefore indicates an overestimation, and a negative error an underestimation by the respec- tive method. The different data pre-treating and filling methods were evaluated according to the mean bias error they introduce on a half-hourly basis. Standard deviation of the mean, the minimum and maximum error and the performance over the seasonal course were additional measures for the quality of a method. Methods which showed relative constant errors no matter how many artificial gaps were introduced, were preferred as being more applicable in terms of error estimates for aggregated time periods (see below).

\section{Results}

The following sections describe (1) general observations of gap frequencies, and frequency distributions of gap lengths, (2) the results of the sensitivity analysis of the gap filling methods on the data for four sites, and (3) the application of the selected methods to 28 data sets and the evaluation of the overall impacts of gap filling on the estimation of daily, monthly and annual sums of $F_{\mathrm{NEE}}$.

\subsection{General observations}

The 28 data sets had an average 35\% missing or rejected $F_{\text {NEE }}$ data that amounted to about 6000 half-hour values for a year (Table 2), with a slightly higher percentage for night observations. Over 50\% of the gaps were less than four periods ( $2 \mathrm{~h}$ ), and less than $4 \%$ were longer than 1000 periods (21 days) (Fig. 1). Although wind speed and friction velocity measurements averaged about 15 and 20\% missing, respectively, other energy flux and meteorology measurements averaged below 10\% (Table 3). When there were partial data for the period, the gaps in the micrometeorology were filled using the methods described in Section 2.3.1 above.

The performance of filling missing or rejected values in a half-hourly data set, or calculating annual sums from incomplete data sets depends on the randomness of the gap distribution. Gaps in $F_{\mathrm{NEE}}$, however, do not occur randomly in the data. Fig. 1 shows for 28 data sets from the EUROFLUX and AmeriFlux projects (Table 1) the number of occurrences of gaps of a certain length (in half-hours). In the top panel the frequency of gap lengths are compared for the average of 28 data sets and the average of 28 sets 

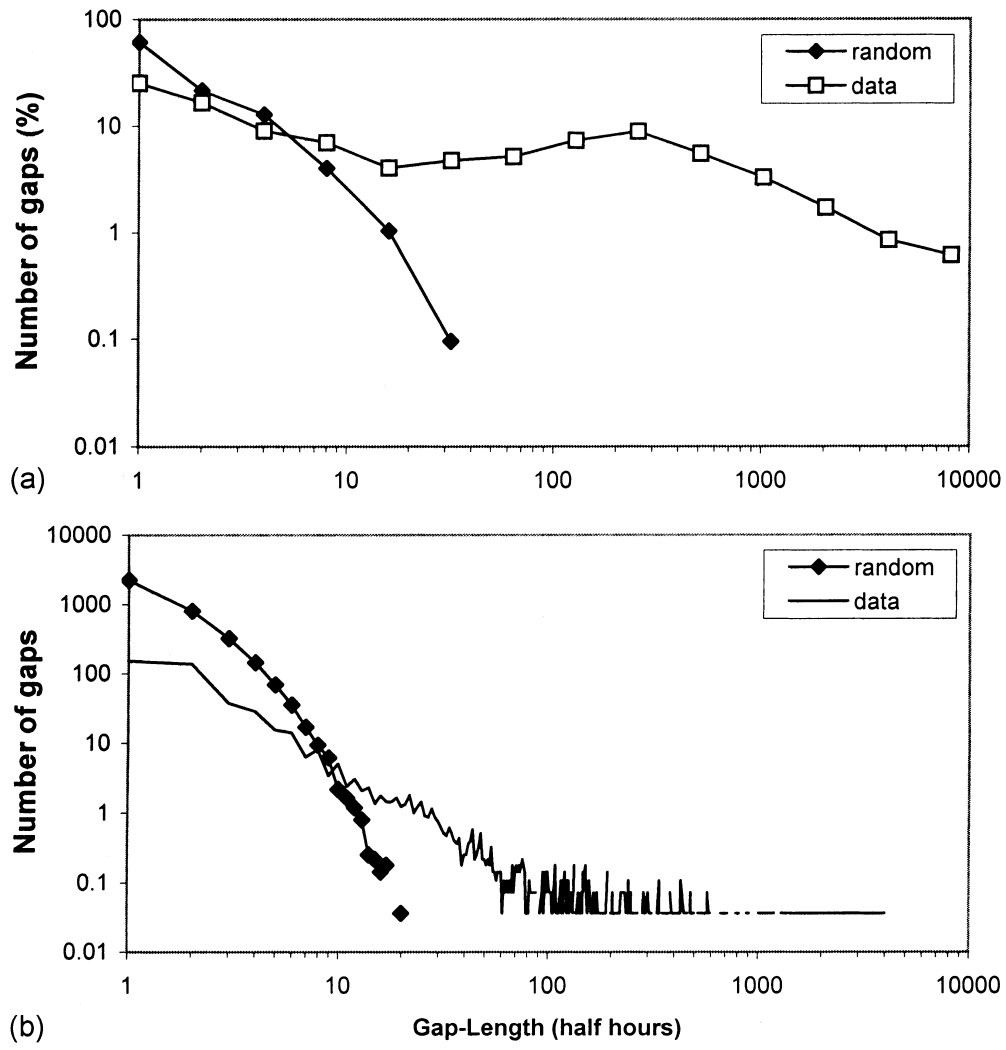

Fig. 1. Frequency of gaps of lengths observed in the investigated data sets of $F_{\mathrm{NEE}}$ (net ecosystem exchange of $\mathrm{CO}_{2}, \mu \mathrm{mol} \mathrm{m}^{-2} \mathrm{~s}^{-1}$ ). (a) Averaged for all sites in comparison with assumed random gap distribution for all sites, normalized, so that the area below the curve equals $100 \%$; (b) as (a) but actual counts; values smaller than 1 on the $y$-axis result from averaging observations of 28 data sets.

with a random gap distribution (but keeping the original gap percentage). The data are normalized, so that the area below each curve sums to $100 \%$. The lower panel shows the actual counts of each length, averaged for the data sets, and a respective average for 28 sets with a random gap distribution. Major differences in the computed gap frequencies are expected depending on the different approaches of data rejec- tion. Some sites report all data where the instruments were working and leave data rejection to be done later, others apply sophisticated quality assurance routines. Harmonization of quality assurance in a data base however can only be accomplished when data archives are provided with raw data and additional information on the status of the data (e.g. rejection criteria).

Table 3

Average percentages for meteorological data, that was missing or had to be rejected for 18 sites from the EUROFLUX and AmeriFlux projects and several years ${ }^{\mathrm{a}}$

\begin{tabular}{llllllllllll}
\hline Gap\% & $R_{\mathrm{n}}$ & $Q_{\text {PPFD }}$ & $R_{\mathrm{g}}$ & $T_{\mathrm{a}}$ & $T_{\mathrm{s}}$ & VPD & $u_{*}$ & $\mathrm{RH}$ & $u$ & Precipitation & $P_{\mathrm{a}}$ \\
\hline Day & 6.0 & 6.8 & 6.7 & 6.6 & 8.4 & 10.5 & 19.8 & 7.5 & 14.3 & 3.7 & 3.6 \\
Total & 6.2 & 3.7 & 3.6 & 6.5 & 8.8 & 10.4 & 20.5 & 7.5 & 14.5 & 4.3 & 4.1 \\
Night & 6.4 & 0.6 & 0.5 & 6.4 & 9.3 & 10.3 & 21.2 & 7.5 & 14.8 & 4.9 & 4.6 \\
\hline
\end{tabular}

${ }^{a}$ For variable abbreviations see Nomenclature. Sites, which did not provide a variable, were not included in the calculation of the percentage. 


\subsection{Sensitivity analysis of filling methods}

We investigated the results of the artificial gap experiment on five levels of gap percentage, and concentrated on methods with good performance over the entire range. In the following, however, we show only results for the average level of $35 \%$ gaps. For each of the three major classes (mean diurnal variation "MDV", look-up tables "LookUp", and nonlinear regression "Regr."), we determined the method which gave the closest approximations of the original data according to our analysis (details in Appendix A). Mean errors (difference between original and filled-in value), the standard deviation from the mean, skewness and kurtosis of the error distribution were calculated for all methods, sites, and gap levels. Low standard deviations and kurtosis values were the measures we used for the assessment. Table 4 shows the results at a level of $35 \%$ artificial gaps for these selected methods and each of the sites investigated as representative for coniferous and broad-leaved forest, crops, and grassland. The values of mean errors although all are close to zero - cannot be used for assigning preferences in methods for functional types, as the variability between gap percent levels is high (data not shown). However, the lower standard deviation of the mean and skewness for coniferous forests hold for all gap percent levels.

In general, applying "MDV" was most stable, i.e. resulting in good approximations of the original data even at high percentage of missing data, and had the lowest bias using 7-day independent windows during night, 14-day during daytime. Application of "LookUp" performed best based on bimonthly periods, using the $Q_{\mathrm{PPFD}}-T_{\mathrm{a}}$-sort during day, and $T_{\mathrm{s}}$-sort during night. For "Regr." during the day,

Table 4

Mean absolute error of $F_{\mathrm{NEE}}$ (net ecosystem exchange, in $\mu \mathrm{mol} \mathrm{m} \mathrm{m}^{-2} \mathrm{~s}^{-1}$ ), calculated as the difference between measured and computed value, and standard deviation from the mean, skewness and kurtosis of the error ${ }^{\mathrm{a}}$

\begin{tabular}{|c|c|c|c|c|c|c|c|}
\hline \multirow{2}{*}{$\begin{array}{l}\text { Error of half-hourly } \\
F_{\mathrm{NEE}} \text { (for } 35 \% \text { artificial gaps) }\end{array}$} & \multicolumn{3}{|c|}{ Daytime data } & \multicolumn{4}{|c|}{ Nighttime data } \\
\hline & MDV & LookUp & Regr. & MDV & LookUp & Regr. $u_{*}$-corrected & Regr. not $u_{*}$-corrected \\
\hline \multicolumn{8}{|l|}{ Average } \\
\hline Conifer & -0.119 & -0.103 & -0.019 & 0.019 & 0.017 & -0.007 & -0.062 \\
\hline Deciduous & -0.123 & -0.121 & -0.160 & 0.040 & 0.061 & 0.068 & 0.020 \\
\hline Crops & 0.142 & 0.100 & 0.141 & -0.050 & 0.026 & -0.035 & 0.053 \\
\hline Grasslands & -0.014 & 0.033 & 0.004 & -0.018 & -0.009 & -0.077 & -0.028 \\
\hline \multicolumn{8}{|l|}{ S.D. } \\
\hline Conifer & 2.64 & 2.26 & 1.94 & 0.79 & 0.66 & 0.74 & 1.14 \\
\hline Deciduous & 3.96 & 3.14 & 3.11 & 1.46 & 1.24 & 1.35 & 2.02 \\
\hline Crops & 4.67 & 4.83 & 4.67 & 1.89 & 1.61 & 1.64 & 1.86 \\
\hline Grasslands & 3.56 & 3.14 & 3.84 & 1.08 & 0.89 & 1.33 & 1.83 \\
\hline \multicolumn{8}{|l|}{ Skewness } \\
\hline Conifer & 0.51 & -0.64 & 0.27 & 0.95 & 2.53 & 1.74 & 0.19 \\
\hline Deciduous & 0.64 & 0.06 & 0.15 & 2.28 & 3.57 & 3.04 & 2.06 \\
\hline Crops & 1.04 & -0.19 & 0.22 & -1.53 & -2.28 & -2.05 & -1.41 \\
\hline Grasslands & 1.34 & -0.61 & -0.08 & -0.46 & -0.67 & -0.53 & -0.17 \\
\hline \multicolumn{8}{|l|}{ Kurtosis } \\
\hline Conifer & 4.18 & 9.04 & 6.31 & 15.38 & 30.93 & 18.84 & 11.31 \\
\hline Deciduous & 5.32 & 6.17 & 5.42 & 18.35 & 27.98 & 21.75 & 12.30 \\
\hline Crops & 9.97 & 7.21 & 9.05 & 27.12 & 33.21 & 30.35 & 21.28 \\
\hline Grasslands & 9.77 & 6.37 & 6.41 & 5.80 & 8.09 & 6.97 & 6.10 \\
\hline
\end{tabular}

a Shown at 35\% artificial gap level in the HY97 (conifers), HV96 (deciduous forest), BV97 (crops), and SH97 (grassland) data sets for the selected gap filling methods: mean diurnal variation MDV, look-up tables LookUp, and nonlinear regressions, Regr. The latter was applied to data sets that were either $u_{*}$-corrected or not $u_{*}$-corrected, details of this correction are given in Appendix A. 
bimonthly periods were preferred with $T_{\mathrm{a}}$-sort for Michaelis-Menten-type equations. However, they failed for data sets with long-term system breakdowns, i.e. longer than 2 months (see filling of individual sites below). Then seasonal periods must be assigned for the gap filling, and site-specific information on season length must be provided. During the night good performance was achieved by four seasonal periods for Lloyd \& Taylor-type equation using $T_{\mathrm{S}}$ as driver, for both $u_{*}$-corrected, and not $u_{*}$-corrected.

The performance of the selected methods (in the sense of small errors and good retrieval of original values) held across the four sites we investigated, and several levels of gap percentages. Specifically, methods with errors more or less constant for a broad band of gap percentage in the data are more applicable in terms of error assignment for new data sets (see below).

Filling daytime data gaps by mean diurnal variation produces estimates that are, on average, less negative than the measurements. This result is produced when nonlinear responses are not considered. The average $F_{\mathrm{NEE}}$ for a given daytime data bin, $\overline{f(x)}$, is generally less negative than a value of $F_{\mathrm{NEE}}$ expected at the average light conditions during that bin, $f(\bar{x})$, (Jensen's inequality for a function $f(x)$, with $f(x)<0$ and $f^{\prime \prime}(x)<0, f^{\prime \prime}(x)$ is the second derivative of $\left.f(x)\right)$. In contrast, a positive mean bias error was typically observed during nighttime for "MDV" (Table 4). This overestimation was also expected, because the basic response of nighttime $F_{\mathrm{NEE}}$ to climatic variables (e.g. temperature) followed a function $f(x)$, with $f(x)>0$ and $f^{\prime \prime}(x)>0$, and subsequently $f(\bar{x})-\overline{f(x)} \geq 0$. Given more linear responses, especially for light, as reported for some ecosystems (crops or grassland, Ruimy et al., 1995), these effects are expected to fade.

Unexpectedly, a negative bias error was observed during the day for semi-empirical gap-filling methods ("LookUp" and "Regr." in Table 4). However, looking at the results for the four sites separately we observe errors close to zero for conifers (HY97), and grasslands (SH97), whereas the mean error was mostly negative for the deciduous forest (HV96). This suggests either the need for a different shape of the light response curve for HV96, or more repetitions of filling artificial gaps. Due to the substantial amount of computer time required for this procedure, gap filling on each percentage level was performed only once. For gap levels of 25 and $45 \%$, the mean bias error for HV96 daytime data was positive. A different light response curve, i.e. steeper for low and flatter for higher light intensities is supported by bias errors closer to zero (but still negative) for the look-up table methods, which do not prescribe the shape of the curve.

To test whether the performance of the methods was due to error compensation over the course of the year, we looked at aggregated errors for each day. Fig. 2 shows the cumulative error over the course of the year for the selected methods (MDV, LookUp, and Regr.) and separated in daytime and nighttime contribution. The data are based on data sets with $35 \%$ artificial gaps. All filling methods are based on an average error close to zero. This can lead to data subsets partly overor underestimated, with compensating errors over the entire period (e.g. daytime BV97 data set in Fig. 2). In this case, and probably for crops in general, the pattern could be improved by assigning gap-filling periods specifically designed to match the local growing cycle of the species. Overall, the cumulative error sum for the sites is small compared to the annual sum of $F_{\mathrm{NEE}}$, ranging between -20 and $+20 \mathrm{~g} \mathrm{C} \mathrm{m}^{-2}$.

The relationship between overall gap percentage and errors summed for different time periods are shown in Fig. 3 for the three selected methods (MDV, LookUp, and Regr.) during daytime. The error was larger when more gaps had been filled for one time period, but this is trivial because the error sum for a record of twice as many gaps should be at least doubled. Moreover, the summed errors are directly proportional to the gap percentage, because we selected methods for which errors would be stable for various gap percentages. Between time periods however, the error sum for a given gap percentage does not scale directly. The errors are mostly random errors, and therefore partly compensate during time integration. Note that the selected methods did not differ much in the error they introduced. In Table 5, the maximum absolute errors are given based on $1 \%$ gaps during a period, and for each of the selected methods. These errors were used to assign the final errors for the filling of the original data sets, depending on how much gaps were filled for a particular data set and time period.

Based on these errors, look-up tables were derived for the various methods. They were created for each of the four sites (HY97, HV96, BV97, and SH97) on a daily, weekly, monthly, and yearly basis. 

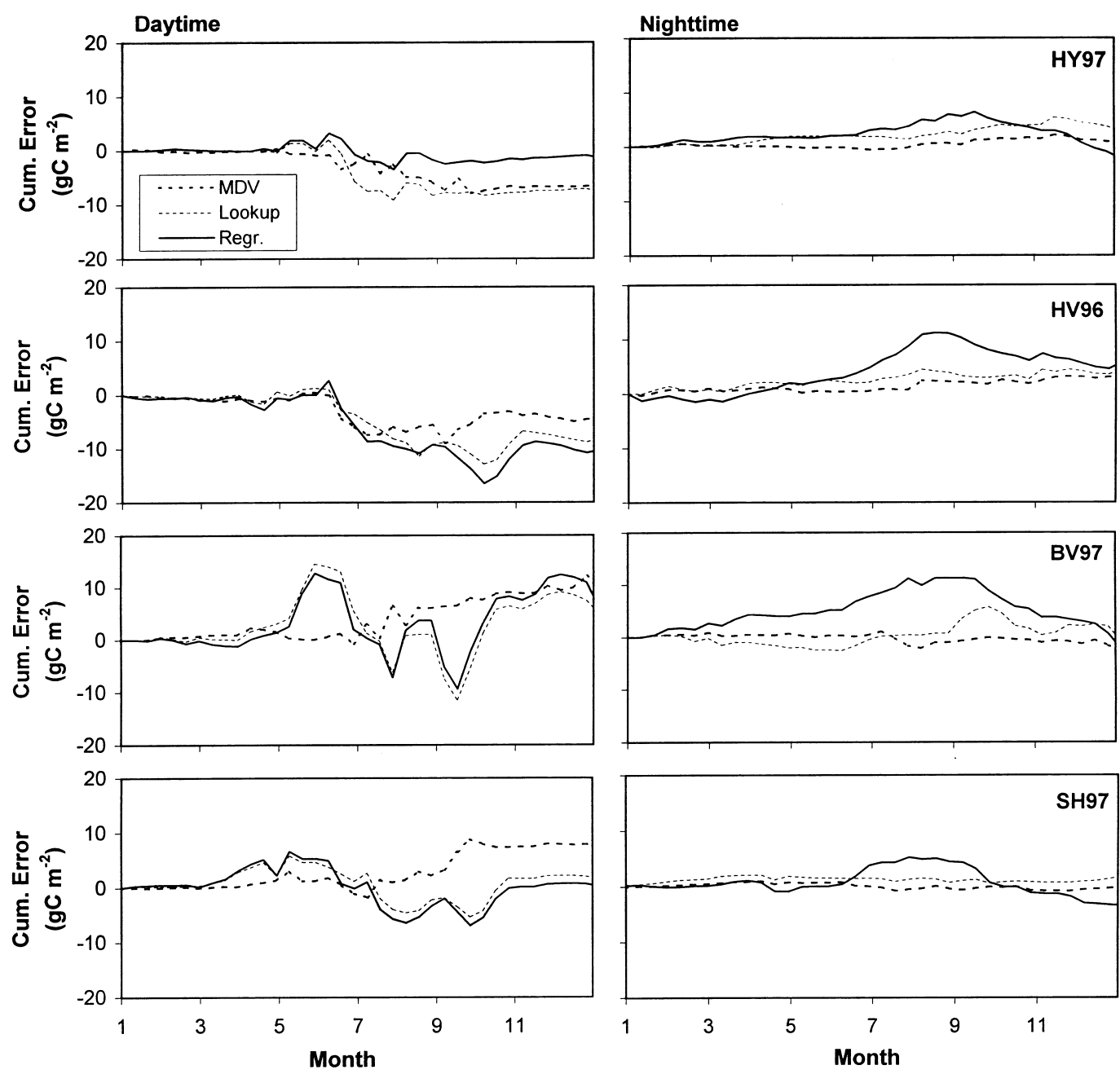

Fig. 2. Cumulative error for $F_{\mathrm{NEE}}$ (net ecosystem exchange), separated in daytime and nighttime contribution, over the course of the year for selected filling methods, mean diurnal variation (MDV), look-up tables (LookUp), and nonlinear regression (Regr.) at the sites Hyytiala (HY97), Harvard Forest (HV96), Bondville (BV97), and Shidler (SH97).

The percentage of gaps filled during day and night for a given time period was used to scale the tabulated values to an error assessment for the period (Table 5, errors in $\mathrm{g} \mathrm{Cm}^{-2}$ per gap\% for the dayor nighttime period). For daytime, errors range from 0.04 to $0.2 \mathrm{~g} \mathrm{C} \mathrm{m}^{-2}$ per percentage of day filled, $0.10-0.64 \mathrm{~g} \mathrm{C} \mathrm{m}^{-2}$ per percentage of month filled, and $0.11-0.83 \mathrm{~g} \mathrm{C} \mathrm{m}^{-2}$ per percentage of year filled. The errors for nighttime gaps were in general smaller, 0.01-0.14, 0.04-0.32, and 0.07-0.52, respectively. During the day, the largest errors were observed for crops, and during night, the errors were largest for grasslands. Comparing different filling methods, the errors are similar during the day, and the Regr. methods resulted in the largest errors during the night.

Assuming that the selection of the "best" filling methods and the error estimates derived for four sites are valid for other data sets and that they are time invariant, we have applied them within each functional group, i.e. conifers, deciduous forests, crops, and grassland. 


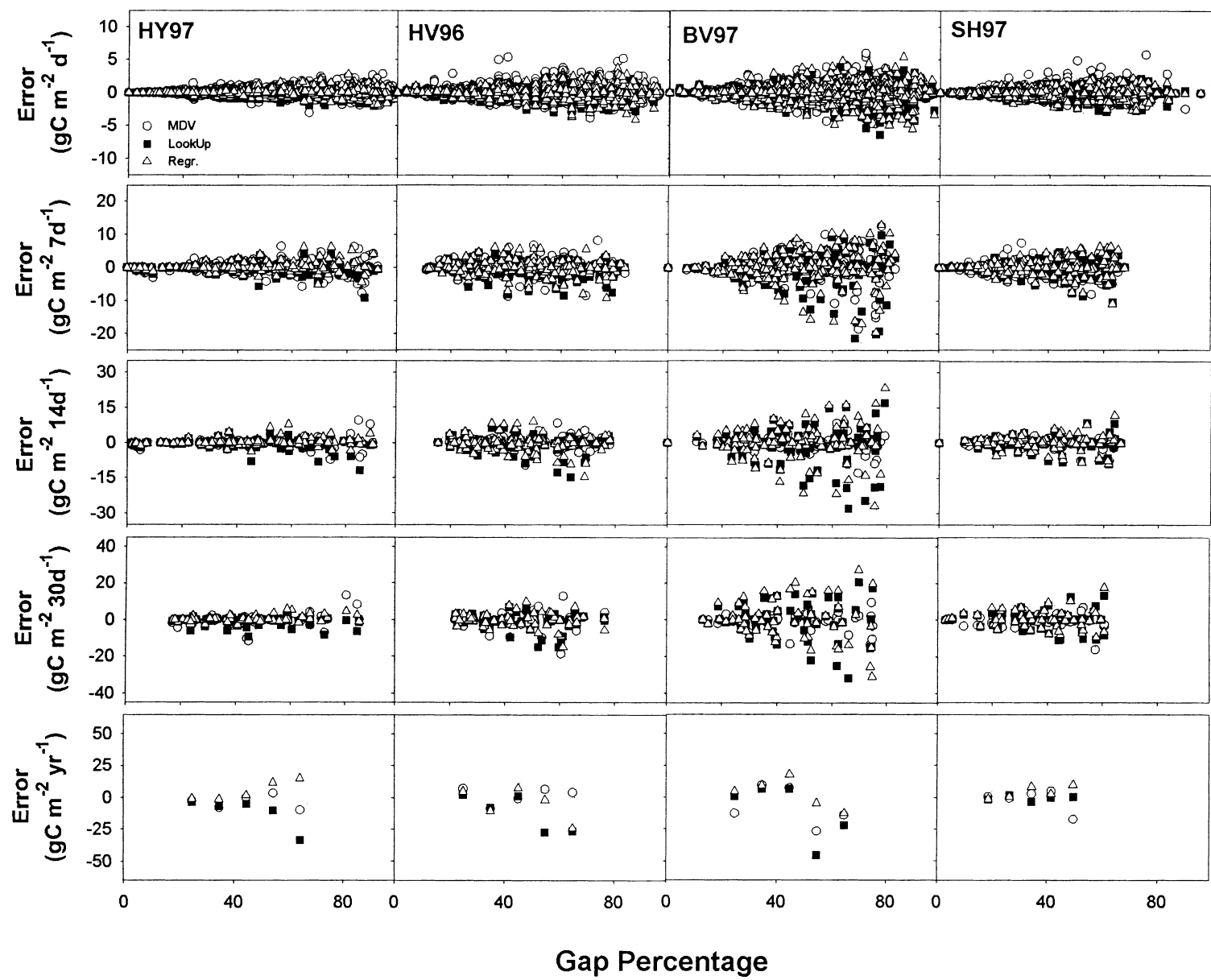

Fig. 3. Dependence of the error sums for daytime $F_{\mathrm{NEE}}$ (net ecosystem exchange) on the filled gap percentage, evaluated for daily (top-most panel), weekly, bi-weekly, monthly, and yearly (lowest panel) time steps, for three selected filling methods (mean diurnal variation: MDV, look-up tables: LookUp, and nonlinear regressions: Regr.) and four sites Hyytiala (HY97), Harvard Forest (HV96), Bondville (BV97), and Shidler (SH97).

\subsection{Application to 28 data sets of $F_{N E E}$}

Based on the results above we applied three different methods (MDV, LookUp, and Regr.) to fill half-hourly data sets for computation of daily, monthly, and annual sums (Table 6). For exceptionally long periods of gaps in the data, however, we had to use data from "previous" periods to extrapolate into the gap, despite an unsatisfying performance of the gliding window-type. There were seven data sets (LO97, BR97, HL96, HV91, LW96, ME96, and ME97) with longer periods of system breakdowns or high percentage of missing data. For these sites we applied the above methods, but used four seasonal periods instead of bimonthly, because the latter lead to unreasonable results over the course of the year.

Finally, we assessed error due to filling in order to evaluate the computed fluxes. The error assigned for the filled data points were taken from look-up tables derived from the results of the sensitivity analysis of the various methods (Table 5).

Filling results varied most when the data set contains large gaps, e.g. due to system breakdown, where sound response functions for filling strategies cannot 
Table 5

Maximum absolute errors (in $\mathrm{g} \mathrm{C}$ per $\mathrm{m}^{2}$ and gap percentage of period) observed for the four selected sites during the artificial gap filling experiment, for three selected filling methods (MDV: mean diurnal variation, LookUp: look-up tables and Regr.: nonlinear regression, as defined in text) and for daytime and nighttime separately ${ }^{\mathrm{a}}$

\begin{tabular}{|c|c|c|c|c|c|c|c|c|c|}
\hline \multirow[t]{2}{*}{ Period } & \multirow[t]{2}{*}{ Method } & \multicolumn{4}{|c|}{$\begin{array}{l}\text { Daytime: absolute }( \pm) \text { error } \\
\left(\mathrm{g} \mathrm{C} \mathrm{m}^{-2} \text { per gap\% of period }\right)\end{array}$} & \multicolumn{4}{|c|}{$\begin{array}{l}\text { Nighttime: absolute }( \pm) \text { error } \\
\left(\mathrm{g} \mathrm{C} \mathrm{m}^{-2} \text { per gap } \% \text { of period }\right)\end{array}$} \\
\hline & & Coniferous & Deciduous & Crops & Grasslands & Coniferous & Deciduous & Crops & Grasslands \\
\hline \multirow[t]{4}{*}{1 Day } & MDV & 0.065 & 0.150 & 0.125 & 0.100 & 0.015 & 0.040 & 0.135 & 0.025 \\
\hline & LookUp & 0.040 & 0.130 & 0.200 & 0.055 & 0.010 & 0.025 & 0.125 & 0.015 \\
\hline & Regr. $\left(u_{*}\right)$ & 0.035 & 0.155 & 0.170 & 0.065 & 0.020 & 0.030 & 0.135 & 0.030 \\
\hline & Regr. (not $u_{*}$ ) & - & - & - & - & 0.020 & 0.040 & 0.125 & 0.030 \\
\hline \multirow[t]{4}{*}{7 Days } & MDV & 0.300 & 0.215 & 0.270 & 0.250 & 0.025 & 0.055 & 0.155 & 0.075 \\
\hline & LookUp & 0.260 & 0.225 & 0.320 & 0.165 & 0.025 & 0.060 & 0.140 & 0.070 \\
\hline & Regr. $\left(u_{*}\right)$ & 0.160 & 0.180 & 0.305 & 0.175 & 0.060 & 0.085 & 0.190 & 0.110 \\
\hline & Regr. (not $u_{*}$ ) & - & - & - & - & 0.065 & 0.140 & 0.175 & 0.100 \\
\hline \multirow[t]{4}{*}{14 Days } & MDV & 0.200 & 0.210 & 0.190 & 0.115 & 0.055 & 0.060 & 0.105 & 0.055 \\
\hline & LookUp & 0.310 & 0.230 & 0.425 & 0.195 & 0.055 & 0.060 & 0.090 & 0.045 \\
\hline & Regr. $\left(u_{*}\right)$ & 0.315 & 0.235 & 0.440 & 0.260 & 0.115 & 0.115 & 0.190 & 0.145 \\
\hline & Regr. (not $u_{*}$ ) & - & - & - & - & 0.115 & 0.095 & 0.185 & 0.145 \\
\hline \multirow[t]{4}{*}{30 Days } & MDV & 0.260 & 0.310 & 0.290 & 0.330 & 0.040 & 0.060 & 0.105 & 0.095 \\
\hline & LookUp & 0.255 & 0.290 & 0.640 & 0.310 & 0.040 & 0.070 & 0.130 & 0.085 \\
\hline & Regr. $\left(u_{*}\right)$ & 0.100 & 0.250 & 0.500 & 0.385 & 0.220 & 0.175 & 0.295 & 0.320 \\
\hline & Regr. (not $u_{*}$ ) & - & - & - & - & 0.200 & 0.185 & 0.265 & 0.260 \\
\hline \multirow[t]{4}{*}{365 Days } & MDV & 0.230 & 0.290 & 0.505 & 0.350 & 0.075 & 0.175 & 0.220 & 0.175 \\
\hline & LookUp & 0.520 & 0.500 & 0.830 & 0.110 & 0.110 & 0.165 & 0.190 & 0.175 \\
\hline & Regr. $\left(u_{*}\right)$ & 0.235 & 0.370 & 0.400 & 0.235 & 0.160 & 0.240 & 0.365 & 0.275 \\
\hline & Regr. (not $u_{*}$ ) & - & - & - & - & 0.310 & 0.070 & 0.230 & 0.520 \\
\hline
\end{tabular}

${ }^{a}$ To obtain an absolute error for a certain period, the values for both, daytime and nighttime, have to be multiplied with the respective gap percentage (e.g. 50 if half of the daytime data are missing), and the results be added. For instance, for $35 \%$ missing values during day and $40 \%$ during night, the LookUp method for "Crops" (BV97) would result in a maximum error of $\pm 36.65 \mathrm{~g} \mathrm{C} \mathrm{m}^{-2}$ per year $(=0.830 \times 35+0.190 \times 40)$.

be determined. In this case, the maximum difference in the filled annual sums reached up to $200 \mathrm{~g} \mathrm{C} \mathrm{m}^{-2}$ per year when we compared mean diurnal variation methods with regression methods, and up to $150 \mathrm{~g} \mathrm{C} \mathrm{m}^{-2}$ per year comparing look-up table methods with regression methods (Fig. 4). On average (and as expected, see Section 3.2) regression methods for $F_{\mathrm{NEE}}$ resulted in more negative values (average difference $-16 \mathrm{~g} \mathrm{C} \mathrm{m}^{-2}$ per year) than those derived via mean diurnal variation.

\section{Discussion}

\subsection{Is there a universal filling strategy for all sites?}

Although the filling methods parameterized for this analysis have been used by others (e.g. Greco and
Baldocchi, 1996; Goulden et al., 1996b; Granier et al., 2000; Pilegaard et al., 2000; Aubinet et al., 2000), comparative studies on the effects of filling methods have not been reported. In this paper, we established that mean diurnal variation can be best applied using 7-day windows during night, and 14-day windows during day. We found that semi-empirical methods (seasonal lookup tables and nonlinear regressions) performed better by applying a high level of resolution in the sort levels (e.g. several periods through the year, and several temperature classes). In addition, statistical analysis associated with the parameterization of non-linear gap filling equations was used to determine the most appropriate equations. For filling daytime gaps, the Michaelis-Menten, or Misterlich functions (Appendix A, Eqs. (A.7)-(A.10)), were selected because residual analysis showed a better overall perfor- 
Table 6

Average annual sum of $\mathrm{F}_{\mathrm{NEE}}$ (net ecosystem exchange) and absolute errors, derived from eddy covariance data ${ }^{\mathrm{a}}$

\begin{tabular}{|c|c|c|c|c|c|c|c|c|c|c|}
\hline \multirow[t]{2}{*}{ Site } & \multicolumn{2}{|c|}{$\begin{array}{l}\text { MDV } u_{*} \text {-corrected } \\
\left(\mathrm{g} \mathrm{C} \mathrm{m}^{-2} \text { per year }\right)\end{array}$} & \multicolumn{2}{|c|}{$\begin{array}{l}\text { LookUp } u_{*} \text {-corrected } \\
\left(\mathrm{g} \mathrm{C} \mathrm{m}^{-2} \text { per year }\right)\end{array}$} & \multicolumn{2}{|c|}{$\begin{array}{l}\text { Regr. } u_{*} \text {-corrected } \\
\left(\mathrm{g} \mathrm{C} \mathrm{m}^{-2} \text { per year }\right)\end{array}$} & \multicolumn{2}{|c|}{$\begin{array}{l}\text { Regr. not } u_{*} \text {-corrected } \\
\left(\mathrm{g} \mathrm{C} \mathrm{m}^{-2} \text { per year }\right)\end{array}$} & \multicolumn{2}{|c|}{$\begin{array}{l}\text { Reported in literature } \\
\left(\mathrm{g} \mathrm{C} \mathrm{m}^{-2} \text { per year }\right)\end{array}$} \\
\hline & $F_{\mathrm{NEE}}$ & Errors & $F_{\mathrm{NEE}}$ & Errors & $F_{\mathrm{NEE}}$ & Errors & $F_{\mathrm{NEE}}$ & Errors & $F_{\mathrm{NEE}}$ & Reference \\
\hline WE97 & 177 & 37 & 114 & 23 & 104 & 23 & -43 & 33 & -77 & Valentini et al. (2000) \\
\hline TH97 & -605 & 22 & -603 & 15 & -608 & 15 & -628 & 21 & -480 & Valentini et al. (2000) \\
\hline VI97 & -328 & 26 & -359 & 27 & -368 & 27 & -393 & 16 & -440 & Valentini et al. (2000) \\
\hline LO97 & -358 & 22 & -363 & 14 & -358 & 14 & -358 & 19 & -210 & Valentini et al. (2000) \\
\hline SO97 & 3 & 6 & 0 & 5 & -3 & 5 & -76 & 4 & $\begin{array}{r}-90 \\
-122\end{array}$ & $\begin{array}{l}\text { Valentini et al. (2000) } \\
\text { Pilegaard et al. (2000) }\end{array}$ \\
\hline HY97 & -272 & 17 & -260 & 10 & -266 & 10 & -318 & 13 & -245 & Valentini et al. (2000) \\
\hline HE97 & -144 & 7 & -153 & 7 & -158 & 7 & -273 & 4 & -260 & Valentini et al. (2000) \\
\hline BR97 & 127 & 41 & 74 & 26 & -74 & 26 & -95 & 36 & $\begin{array}{r}60 \\
-157\end{array}$ & $\begin{array}{l}\text { Valentini et al. (2000) } \\
\text { Kowalski et al. (1999) }\end{array}$ \\
\hline AB97 & -614 & 17 & -604 & 11 & -624 & 11 & -697 & 15 & -670 & Valentini et al. (2000) \\
\hline WB95 & -544 & 16 & -517 & 15 & -519 & 15 & -584 & 10 & & \\
\hline WB96 & -796 & 16 & -734 & 15 & -738 & 15 & -791 & 10 & & \\
\hline WB97 & -791 & 19 & -698 & 18 & -721 & 18 & -751 & 12 & -662 & Hollinger et al. (2000) \\
\hline HL96 & -321 & 29 & -258 & 18 & -278 & 18 & -278 & 25 & -210 & Hollinger et al. (2000) \\
\hline HV92 & -189 & 28 & -324 & 25 & -338 & 25 & -424 & 19 & & \\
\hline HV93 & -210 & 31 & -228 & 28 & -225 & 28 & -307 & 21 & & \\
\hline HV94 & -175 & 14 & -162 & 12 & -158 & 12 & -233 & 9 & -212 & Hollinger et al. (2000) \\
\hline HV95 & -230 & 17 & -227 & 15 & -229 & 15 & -351 & 11 & -208 & Hollinger et al. (2000) \\
\hline HV96 & -191 & 12 & -170 & 11 & -172 & 11 & -269 & 8 & -260 & Hollinger et al. (2000) \\
\hline LW97 & 150 & 6 & 131 & 10 & 148 & 10 & 57 & 16 & 41 & Hollinger et al. (2000) \\
\hline LW98 & 521 & 7 & 436 & 13 & 467 & 13 & 403 & 19 & 419 & Hollinger et al. (2000) \\
\hline BV97 & -563 & 20 & -543 & 16 & -526 & 16 & -547 & 13 & -467 & Hollinger et al. (2000) \\
\hline BV98 & 125 & 25 & 133 & 21 & 165 & 21 & 129 & 16 & & \\
\hline SH97 & -383 & 8 & -349 & 14 & -355 & 14 & -431 & 21 & -318 & Hollinger et al. (2000) \\
\hline PO97 & -147 & 41 & -155 & 30 & -174 & 30 & -249 & 25 & -183 & Hollinger et al. (2000) \\
\hline ME96 & -308 & 16 & -287 & 11 & -325 & 11 & -325 & 17 & $\begin{array}{l}-333 \\
-320 \pm 170\end{array}$ & $\begin{array}{l}\text { Hollinger et al. (2000) } \\
\text { Anthoni et al. (1999) }\end{array}$ \\
\hline ME97 & -328 & 26 & -264 & 17 & -324 & 17 & -324 & 24 & $\begin{array}{l}-267 \\
-270 \pm 180\end{array}$ & $\begin{array}{l}\text { Hollinger et al. (2000) } \\
\text { Anthoni et al. (1999) }\end{array}$ \\
\hline DU98 & -566 & 40 & -555 & 36 & -585 & 36 & -710 & 26 & -650 & Katul et al. (2000) \\
\hline DU99 & -708 & 27 & -649 & 25 & -666 & 25 & -850 & 18 & & \\
\hline
\end{tabular}

${ }^{\text {a }}$ Results for three methodologies of gap-filling are reported separately: filling by mean diurnal variation of prescribed periods (MDV), and filling by semi-empirical methods, look-up tables (LookUp) and nonlinear regression (Regr.) as discussed in the text. Results from the nonlinear regression method are reported for data, which were $u_{*}$-corrected (for WB advection corrected) and not $u_{*}$-corrected. Details of this correction are given in Appendix A. Reported values of annual $F_{\mathrm{NEE}}$ for the respective site are given when available. For site abbreviations see Table 1 .

mance. For filling nighttime gaps, the Lloyd \& Taylor, Arrhenius, and Van't Hoff methods (Appendix A, Eqs. (A.3)-(A.5)) could not be distinguished via analyzing residuals, due to the large variability in the data.

The sensitivity analysis of the gap filling methods was performed for four sites, which we selected as representative for the functional groups conifers, deciduous forests, crops, and grassland. Ideally, we would have conducted this analysis for each site. As the performance of differing methods stayed more or less constant between the sites we examined, we expect similar results for other sites in temperate to boreal zones. We have not addressed the issue of gap filling with tropical functional groups, which experience little seasonality. In addition, these results are based only on variations of a small set of basic methods, mean 


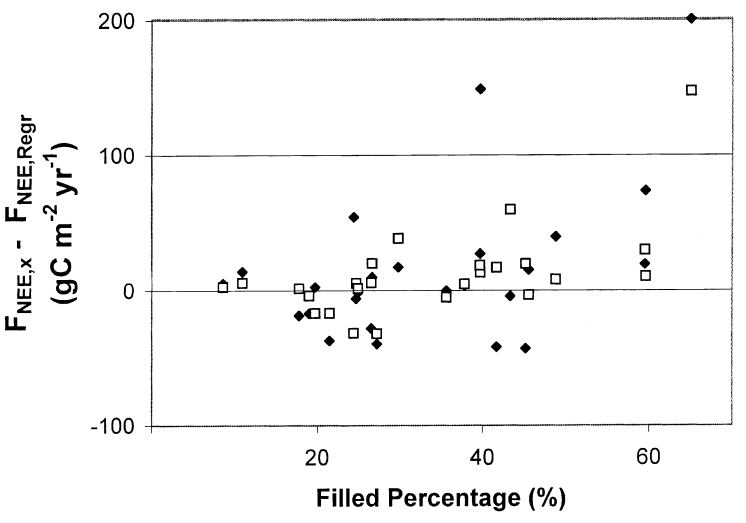

Fig. 4. Difference in annual sums of $F_{\mathrm{NEE}, x}$ (net ecosystem exchange, $x=$ MDV or LookUp) for all sites, filled by the selected filling methods versus gap percentage in the original data sets. Closed symbols represent the difference between methods based on mean diurnal variation (MDV), and the nonlinear regression method (Regr.), open symbols the difference between look-up tables (LookUp), and Regr.

diurnal variation and semi-empirical regressions. Other factors such as vapor pressure deficit, soil water availability or footprint heterogeneity could and should be included to improve the performance.

Annual sums of $F_{\mathrm{NEE}}$ resulting from the selected methods are not necessarily compatible with each other (see Table 6 ). For $u_{*}$-corrected data, $F_{\mathrm{NEE}}$ filled by Regr. generally is more negative than $F_{\mathrm{NEE}}$ filled by MDV (linear coefficients $a=34.35 \mathrm{~g} \mathrm{C} \mathrm{m}^{-2} \mathrm{yr}^{-1}$, $\left.b=0.906, r^{2}=0.97\right)$, whereas $F_{\mathrm{NEE}}$ filled by LookUp is closer to $F_{\mathrm{NEE}}$ filled by Regr. (linear coefficients $a=9.93 \mathrm{~g} \mathrm{C} \mathrm{m}^{-2} \mathrm{yr}^{-1}, b=1.007, r^{2}=$ 0.99). The largest effect is due to pre-treating the data, namely the $u_{*}$-correction, that resulted in a more positive annual $F_{\mathrm{NEE}}$ (with $a=+59.93 \mathrm{~g} \mathrm{C} \mathrm{m}^{-2} \mathrm{yr}^{-1}$, $b=0.987$, and $\left.r^{2}=0.97\right)$. A linear regression between $u_{*}$-corrected $F_{\mathrm{NEE}}$ filled by Regr. and cited values of $F_{\mathrm{NEE}}$ results in $a=+22.41 \mathrm{~g} \mathrm{C} \mathrm{m}^{-2} \mathrm{yr}^{-1}$, $b=1.079, r^{2}=0.90$, whereas not $u_{*}$-corrected $F_{\mathrm{NEE}}$, filled by Regr. resulted in $a=-44.21 \mathrm{~g} \mathrm{C} \mathrm{m}^{-2} \mathrm{yr}^{-1}$, $b=1.035, r^{2}=0.94$. These results indicate an inconsistency in the use of $u_{*}$-correction of $F_{\mathrm{NEE}}$ in the literature for these sites.

On average, the selected filling methods still resulted in different annual sums. Selection of methods based on the most stable performance (in the sense of good approximation of original values even at high percentages of missing data) and smallest errors therefore did not help in deciding which of the investigated filling methods should be preferred. However, we tend to prefer semi-empirical methods because they preserve the response of $F_{\mathrm{NEE}}$ to main meteorological conditions (e.g. $Q_{\mathrm{PPFD}}$, temperature), an important issue for comparison with estimates from SVAT models (see below). If meteorological variables are not available, methods based on mean diurnal variation of $F_{\mathrm{NEE}}$ (or other filling tools, which we did not include in our analysis, e.g. neural networks, see Aubinet et al., 2000) must be applied regardless of those issues.

\subsection{Is there a solution for the nighttime problem?}

Despite the awareness of the problems in accurately determining nighttime fluxes, no general consensus was found for correcting the fluxes. Chamber measurements of soil, leaf, and stem respiration are viewed as important tools to help understand the relative contributions of the component fluxes of $F_{\mathrm{NEE}}$, and determine fluxes missed by the above-canopy eddy covariance system (e.g. Law et al., 1999a,b). In forest ecosystems continuous below-canopy flux measurements via eddy covariance can be applied as an additional estimate of soil (and trunk) respiration. With ideal terrain and ideal system design, the storage term should account for the underestimation of the eddy covariance measurements during night, although site-specific corrections are being applied for non-ideal conditions. It is still uncertain whether this should include an empirical $u_{*}$-correction, consideration of advection (Lee, 1998; Baldocchi et al., 2000a), or even more complicated approaches.

Theoretically, the storage term can be ignored for daily and annual sums, and doing so would exclude an additional source of variance due to methodology and integrating different source areas of the fluxes. However, with respect to the point discussed in Section 4.4, we applied filling strategies based on half-hourly data, which were corrected for storage if available. Application of the $u_{*}$-correction to the eddy covariance term also might suffer from auto-correlation, as $u_{*}$ is proportional to $\sigma_{w}^{1 / 2}$, and the eddy covariance flux to $\sigma_{w}$.

The effect of a $u_{*}$-correction on the annual sum of $F_{\text {NEE }}$ for all data sets analyzed here was on average $+77 \mathrm{~g} \mathrm{C} \mathrm{m}^{-2}$ per year, but could be as large as $+185 \mathrm{~g} \mathrm{C} \mathrm{m}^{-2}$ per year, accounting for almost 
the average $F_{\mathrm{NEE}}$ of a temperate forest. Excluding sites where no storage term was available, the average was $+65 \mathrm{~g} \mathrm{C} \mathrm{m}^{-2}$ per year, and the maximum was $+147 \mathrm{~g} \mathrm{C} \mathrm{m}^{-2}$ per year. Differences among the sites result partly from ecosystem type: for crops and grassland the effect averages to +60 , for deciduous and coniferous forests to +86 and $+89 \mathrm{~g} \mathrm{C} \mathrm{m}^{-2}$ per year, respectively. The effect of the $u_{*}$-correction increases weakly with leaf area density, defined as LAI $\left(\mathrm{m}^{2} \mathrm{~m}^{-2}\right)$ divided by canopy height $(\mathrm{m})$ with a $r^{2}$ of 0.33 . Topography or fetch might be other variables to investigate, but are not well defined or not yet accessible in the data base. The results suggest that considerable work in terms of methodology and underlying theory will be involved to address problems associated with nighttime fluxes more deeply.

\subsection{Can nighttime carbon fluxes be used to define} ecosystem respiration and gross primary productivity, as are needed to validate ecosystem process models?

In validating ecosystem process models, a suite of ecosystem fluxes $\left(F_{\mathrm{GPP}}, F_{\mathrm{NPP}}, F_{\mathrm{NEP}}, F_{\mathrm{NEE}}, F_{\mathrm{RE}}\right)$ is ideally investigated (e.g. Law et al., 2000). When using eddy covariance data to estimate $F_{\mathrm{GPP}}$ and $F_{\mathrm{RE}}$, we need to first determine whether nighttime conditions or correction methods deliver biologically reasonable results. The ratio we define is simply

$z=\frac{x}{1-y}$

where $y=F_{\mathrm{NPP}} / F_{\mathrm{GPP}}=1-F_{\mathrm{RA}} / F_{\mathrm{GPP}}$ with $0 \leq$ $y \leq 1$, and $x=F_{\mathrm{RA}} / F_{\mathrm{RE}}$ with $0 \leq x \leq 1$.

Given $F_{\mathrm{RE}}$ and $F_{\mathrm{NEP}}, z$ can be calculated from eddy covariance measurements as $F_{\mathrm{NEP}} / F_{\mathrm{RE}}+1$ or $F_{\mathrm{GPP}} / F_{\mathrm{RE}}$. We sorted $F_{\mathrm{GPP}}, F_{\mathrm{NPP}}, F_{\mathrm{NEP}}, F_{\mathrm{RA}}$, and $F_{\mathrm{RH}}$ by their magnitudes, and identified sites that most likely underestimated respiration fluxes according to the following scheme. The 2D space $[x ; y]$ can be sub-divided into five sub-spaces (Fig. 5), according to the relative contribution of $F_{\mathrm{RH}}$ in the system: sub-space I covers $0<z<1 /(2-y)$, i.e. $F_{\mathrm{GPP}}<F_{\mathrm{RH}}$, sub-space II $1 /(2-y)<z<1$, i.e. $F_{\mathrm{NPP}}<F_{\mathrm{RH}}<F_{\mathrm{GPP}}$, sub-space III $1<z<$ $2 /(2-y)$, i.e. $F_{\mathrm{NEP}}<F_{\mathrm{RH}}<F_{\mathrm{NPP}}$, sub-space IV $2 /(2-y)<z<2$, i.e. $F_{\mathrm{NEP}}-F_{\mathrm{RA}}<F_{\mathrm{RH}}<F_{\mathrm{NEP}}$, and sub-space $\mathrm{V} 2<z$, i.e. $F_{\mathrm{RH}}<F_{\mathrm{NEP}}-F_{\mathrm{RA}}$ or $F_{\mathrm{RE}}<F_{\mathrm{NEP}}$.

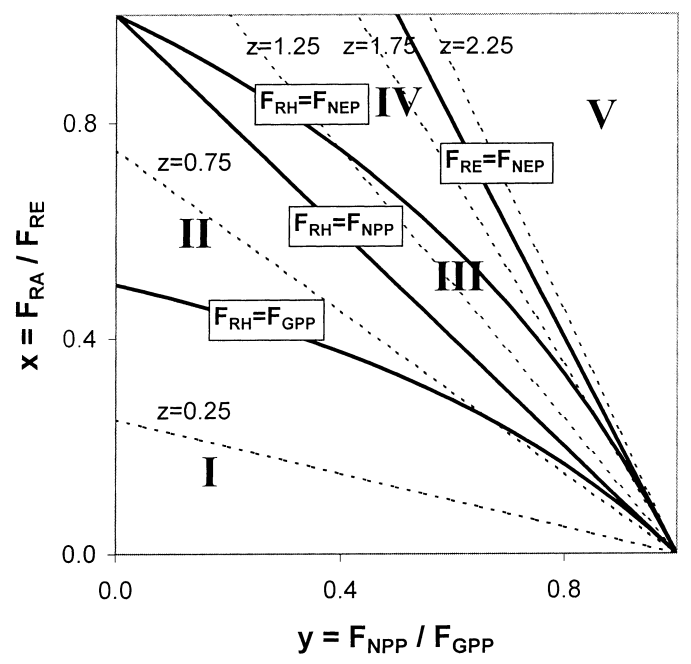

Fig. 5. Conceptual diagram for values of $[x ; y]$ and their importance for potential contribution of $F_{\mathrm{RH}}$ (heterotrophic respiration) to gross primary production $\left(F_{\mathrm{GPP}}\right)$. In the lower left (sub-space I: $F_{\mathrm{RH}}>F_{\mathrm{GPP}}$ ) the system respiration benefits from carbon gain from former years. The diagonal line limits to the left a $F_{\mathrm{NEP}}$ (net ecosystem production) below zero (sub-space II: $F_{\mathrm{GPP}}>F_{\mathrm{RH}}>F_{\mathrm{NPP}}$, with $F_{\mathrm{NPP}}$ net primary production). To the right of the diagonal line $F_{\mathrm{NEP}}$ is above zero (sub-space III: $F_{\mathrm{NPP}}>F_{\mathrm{RH}}>F_{\mathrm{NEP}}$ ). Sub-space IV encloses $F_{\mathrm{RH}}$ between $F_{\mathrm{NEP}}$ and $F_{\mathrm{NEP}}-F_{\mathrm{RA}}$, with $F_{\mathrm{RA}}$ autotrophic respiration. The upper right sub-space $(\mathrm{V})$ indicates low overall contribution of $F_{\mathrm{RH}}$ $\left(F_{\mathrm{NEP}}-F_{\mathrm{RA}}>F_{\mathrm{RH}}\right)$. Five dashed lines indicate potential values of $z=x /(1-y)$, covering the range of $z\left(=F_{\mathrm{NEP}} / F_{\mathrm{RE}}+1\right)$ found for the investigated sites, with $F_{\mathrm{RE}}$ ecosystem respiration. The "conservative" ratio $F_{\mathrm{NPP}} / F_{\mathrm{GPP}}$ of 0.47 is not shown (see text, Waring et al., 1998).

We do not know $x$ and $y$ separately, and unfortunately some borders of the sub-spaces are dependent on $y$, the ratio of $F_{\mathrm{NPP}}$ to $F_{\mathrm{GPP}}$. This ratio recently (Waring et al., 1998) was suggested as being conservative $(0.47 \pm 0.04$ S.D. $)$, based on data for 12 evergreen and deciduous forests in USA, Australia, and New Zealand. Other authors set it to 0.5 (Ryan, 1991; Gifford, 1994). However, earlier work (e.g. Edwards et al., 1981) suggested, that the ratio of $F_{\mathrm{RA}}$ to $F_{\mathrm{GPP}}(=1-y)$ is greater in forests with high total standing crop (as a result of a decreased ratio of photosynthetic to non-photosynthetic surface, see also Goetz and Prince, 1998). In terms of production efficiency (y in our terminology), forests with higher total standing crop are less efficient. Therefore, we calculated $x$ as function of $(1-y)$, with $0 \leq y \leq 1$, 
Table 7

Most probable sub-spaces (I-V) for sites according to Fig. 5, and Eq. $(1)^{\mathrm{a}}$

\begin{tabular}{lll}
\hline Site & $z=F_{\text {NEP }} / F_{\text {RE }}+1$ & Sub-space \\
\hline WE97 & 0.92 & II \\
TH97 & 1.58 & IV \\
VI97 & 1.34 & III (-IV) \\
LO97 & 1.20 & III \\
SO97 & 1.00 & II-III \\
HY97 & 1.38 & III (-IV) \\
HE97 & 1.13 & III \\
BR97 & 1.06 & III \\
AB97 & 1.47 & (III-) IV \\
WB95 & 1.74 & IV \\
WB96 & 1.96 & IV-V \\
WB97 & 1.96 & IV-V \\
HL96 & - & - \\
HV92 & 1.41 & (III-) IV \\
HV93 & 1.22 & III \\
HV94 & 1.18 & III \\
HV95 & 1.25 & III \\
HV96 & 1.18 & III \\
LW97 & 0.83 & II \\
LW98 & 0.24 & I \\
BV97 & 1.54 & IV \\
BV98 & 0.80 & II \\
SH97 & 1.25 & III \\
PO97 & 1.12 & III \\
ME96 & - & - \\
ME97 & - & - \\
DU98 & 1.64 & IV \\
DU99 & 1.77 & IV \\
\hline
\end{tabular}

${ }^{a}$ Definitions for the sub-spaces are given in the legend of Fig. 5. $F_{\mathrm{NEP}}$ is net ecosystem production, and $F_{\mathrm{RE}}$ ecosystem respiration. For site abbreviations, see Table 1.

for $z$ between 0.25 and 2.25, using Eq. (1), as viewed in Fig. 5. For the sites here, $z$-values were calculated from $F_{\mathrm{NEP}}$ in Table 6 Regression method, and $F_{\mathrm{RE}}$ from Table 8, to investigate most probable sub-spaces for the data (Table 7). LW98, a rangeland with severe drought, benefits from carbon gain in previous years (sub-space I). WE97, LW97, and BV98 have negative $F_{\mathrm{NEP}}$, falling into sub-space II. Most sites however fall into sub-space III. Sites in sub-space IV include TH97, AB97, HV92, BV97, and DU, whereas WB96 and WB97 fall on the border between sub-space IV and V. Sites in sub-space IV and higher must be carefully examined, whether systematic underestimation of the respiration terms or real processes in the ecosystem are ongoing (BV97 was a corn field, a C4 species; AB97 and DU are high productive plantations). For the sites $\mathrm{HV}$ and DU $u_{*}$-correction was applied despite the fact that no storage data were available in the data sets, resulting eventually in too high $z$-values due to the so-called "double-counting" of storage (see Appendix A, sites indicated in Table 8).

$F_{\mathrm{RE}}$ for the sites (reported in Table 8) are derived from an exponential regression (Arrhenius, Eq. (A.4)) between nighttime fluxes at high friction velocity and soil temperature, evaluated over the entire year. The respective data can also be used to parameterize a Q10 relationship, resulting in Q10 values ranging from 1.5 to 3.7. The average is 2.5 , and the median 2.4. A median of 2.4, however for soil respiration, is reported in Raich and Schlesinger (1992). These authors indicate that their Q10 values are based on seasonal changes in soil temperature and respiration rates, i.e. large values might be caused by pooling data over the course of the year, and therefore include different sources of respiration. This argument applies especially for the values here, as they include leaf, stem and soil respiration, and their respective seasonal trends. However, we would expect Q10 for deciduous forests larger than for coniferous forests: For the former respiring leaves are missing in winter, with presumably lower temperatures, resulting in a relative lower ecosystem respiration flux, which is then compared to an ecosystem respiration (including leaves) in summer, with presumably higher temperatures. In contrast the data at hand show a mean of 2.2 for deciduous, and a mean of 2.7 for coniferous forests.

Besides relations from $u_{*}$-corrected nighttime fluxes, other methods have being investigated to determine $F_{\mathrm{RE}}$. Below-canopy eddy covariance in most cases is only measured during intensive campaigns, and sample - as chamber measurements a different source area than the above-canopy system. Approaches in a recent study (Falge et al., in preparation) include nighttime eddy flux versus soil temperature, but also air temperature dependence of the light response of daytime $F_{\mathrm{NEE}}$ extrapolated to zero light, and up-scaled chamber measurements of leaves, stems, and soil. In general $F_{\mathrm{RE}}$ derived from $u_{*}$-corrected nighttime eddy covariance fluxes give higher annual respiration rates than values extrapolated from daytime light response curves. This might be due to a down-regulation of leaf respiration during 
Table 8

Arrhenius parameters $E_{\mathrm{a}}$ (energy of activation), and $F_{\mathrm{RE}, 283}$ (ecosystem respiration at a temperature of $283 \mathrm{~K}$ ), for the correction for low friction velocities $\left(u_{*}\right)$ for each data set, and the respective $u_{*}$-threshold below which nighttime $F_{\mathrm{NEE}}$ (net ecosystem exchange) was replaced by the calculated value ${ }^{\mathrm{a}}$

\begin{tabular}{|c|c|c|c|c|c|c|c|}
\hline \multirow[t]{2}{*}{ Site } & \multirow[t]{2}{*}{ Storage } & \multicolumn{2}{|c|}{ Arrhenius parameters } & \multirow[t]{2}{*}{$u_{*}\left(\mathrm{~m} \mathrm{~s}^{-1}\right)$} & \multirow{2}{*}{$\begin{array}{l}F_{\mathrm{RE}}\left(\mathrm{g} \mathrm{C} \mathrm{m}^{-2}\right. \\
\text { per year })\end{array}$} & \multicolumn{2}{|l|}{$F_{\mathrm{RE}}$ from literature } \\
\hline & & $E_{\mathrm{a}}\left(\mathrm{J} \mathrm{mol}^{-1}\right)$ & $F_{\mathrm{RE}, 283}\left(\mu \mathrm{mol} \mathrm{m}^{-2} \mathrm{~s}^{-1}\right)$ & & & $\mathrm{gC} \mathrm{m}^{-2}$ per year & Reference \\
\hline WE97 & Yes & 67056 & 4.603 & 0.35 & 1322 & 1300 & Valentini et al. (2000) \\
\hline TH97 & Yes & 81320 & 3.184 & 0.40 & 1042 & 950 & Valentini et al. (2000) \\
\hline VI97 & Yes & 72244 & 3.160 & 0.40 & 1095 & 825 & Valentini et al. (2000) \\
\hline $\mathrm{LO} 97^{\mathrm{b}}$ & Yes & (48367) & $(4.564)$ & $(0.25)$ & 1778 & 1340 & Valentini et al. (2000) \\
\hline SO97 & Yes & 47548 & 3.569 & 0.15 & 1193 & 1060 & Valentini et al. (2000) \\
\hline HY97 & Yes & 77151 & 2.797 & 0.25 & 707 & 760 & Valentini et al. (2000) \\
\hline HE97 & $\mathrm{Yes}^{\mathrm{c}}$ & 56394 & 3.073 & 0.15 & 1230 & 990 & Valentini et al. (2000) \\
\hline BR97 & Yes & 36096 & 2.890 & 0.15 & 1139 & - & - \\
\hline AB97 & $\mathrm{Yes}^{\mathrm{c}}$ & 99789 & 5.270 & 0.25 & 1335 & 1320 & Valentini et al. (2000) \\
\hline $\mathrm{WB}^{\mathrm{d}} 5^{\mathrm{d}}$ & Yes & 39288 & 1.456 & 0.175 & 703 & - & - \\
\hline WB96 $^{\mathrm{d}}$ & Yes & 61450 & 1.334 & 0.175 & 766 & - & - \\
\hline WB97 ${ }^{\mathrm{d}}$ & Yes & 77642 & 1.058 & 0.15 & 750 & - & - \\
\hline HL96 & No & - & - & - & - & - & - \\
\hline HV92 & No & 48265 & 2.126 & 0.30 & 825 & - & - \\
\hline HV93 & No & 31074 & 2.559 & 0.35 & 1035 & - & - \\
\hline HV94 & No & 44162 & 2.377 & 0.30 & 901 & - & - \\
\hline HV95 & No & 48152 & 2.424 & 0.35 & 927 & - & - \\
\hline HV96 & No & 56423 & 2.508 & 0.25 & 970 & - & - \\
\hline LW97 & $\mathrm{NA}^{\mathrm{e}}$ & 87559 & 0.841 & 0.15 & 877 & - & - \\
\hline LW98 & $\mathrm{NA}^{\mathrm{e}}$ & 31028 & 1.132 & 0.15 & 617 & - & - \\
\hline BV97 & $\mathrm{NA}^{\mathrm{e}}$ & 91754 & 0.914 & 0.10 & 983 & - & - \\
\hline BV98 & $\mathrm{NA}^{\mathrm{e}}$ & 71003 & 0.966 & 0.10 & 818 & - & - \\
\hline SH97 & $\mathrm{NA}^{\mathrm{e}}$ & 71769 & 2.293 & 0.15 & 1396 & - & - \\
\hline PO97 & $\mathrm{NA}^{\mathrm{e}}$ & 27729 & 2.796 & 0.25 & 1393 & - & - \\
\hline ME96 & Yes & - & - & - & - & - & - \\
\hline ME97 & Yes & - & - & - & - & - & - \\
\hline DU98 & No & 59096 & 1.487 & 0.15 & 912 & - & - \\
\hline DU99 & No & 46131 & 1.604 & 0.15 & 869 & - & - \\
\hline
\end{tabular}

${ }^{\mathrm{a}}$ For HL96, ME96 and ME97 $u_{*}$ was not available. In addition, ecosystem respiration $\left(F_{\mathrm{RE}}\right)$ was compared with values cited elsewhere. $F_{\mathrm{RE}}$ were calculated by applying the Arrhenius equation (Eq. (A.4)) with the above parameters for soil temperature (for each half-hour), and then summed into annual values. For site abbreviations see Table 1 .

${ }^{\mathrm{b}}$ The data set for LO97 contained both, $u_{*}$-corrected data of $F_{\mathrm{NEE}}$, and the eddy covariance and storage flux separately, the values are given for comparison, but not used.

${ }^{\mathrm{c}}$ Part of the year.

${ }^{\mathrm{d}}$ For WB95-97 the $u_{*}$-correction was applied only during summer, as nighttime data during winter were replaced by modeled values.

${ }^{\mathrm{e}}$ For grasslands and short crops consideration of storage terms is not necessary.

the active phase of the day, resulting - extrapolated for nighttime - in too low estimates. Comparisons with up-scaled chamber respiration measurements were not this consistent: chamber data could exceed or show slightly lower values than the estimate for $F_{\text {RE. }}$ The better agreement between chamber data and $F_{\mathrm{RE}}$ lead us to exclude ecosystem respiration estimates from daytime light response from further analysis, even if daytime eddy covariance measurements should be more reliable than those from nighttime.

The above concept helps constrain the relative contribution of the component fluxes $F_{\mathrm{RA}}, F_{\mathrm{RH}}$, $F_{\mathrm{NEP}}$ to total $F_{\mathrm{GPP}}$. We think, that - together with the interpretative help of stable isotope investigations (e.g. Bowling et al., 1999) — a separation 
of $F_{\mathrm{RA}}$, and $F_{\mathrm{RH}}$, and therefore the derivation of $F_{\mathrm{NPP}}$ (as sum of $F_{\mathrm{NEP}}$ and $F_{\mathrm{RH}}$ ) becomes then more feasible.

\subsection{Does filling preserve responsiveness to meteorological drivers, as are needed to validate SVAT models?}

One of the requirements for comparisons between model output and data on (half-) hourly time steps is a conservation of the response to meteorological drivers even during gap filling. Thus, as a prerequisite at the interface of SVAT model validation and also large scale assessments eddy correlation data should be filled with look up table or nonlinear regression type methods, and mean diurnal variation be avoided. Look up table or nonlinear regression was preferred, as filling methods based on mean diurnal variation result in a shift towards more positive values of carbon uptake and release.

For the same reasons we applied the filling always for half-hourly data, and afterwards summed into daily, monthly or annual values. Predictions of carbon uptake would be on an average less negative than measurements (Jensen's inequality for a function $f(x)<0$ with $f^{\prime \prime}(x)<0: f(\bar{x})-\overline{f(x)} \leq 0$, for details see above), as the nonlinear responses of $F_{\mathrm{NEE}}$ to climatic variables are not considered when meteorological drivers are averaged first into daily, monthly or annual values. For carbon release during night methods based on mean diurnal variation would led to an overestimation by the filling method, as the basic response of nighttime $F_{\mathrm{NEE}}$ to climatic variables (e.g. temperature) follows a function $f(x)>0$ with $f^{\prime \prime}(x)>0$ and $f(\bar{x})-\overline{f(x)}$ $\geq 0$.

Application of the filling on half-hourly time steps is the reason for the differences between the three filling methods being maintained on other temporal resolutions (i.e. daily, weekly, monthly, or annual). Thus, effects of non-standardization are not expected to cancel out, when working with data on coarser temporal resolution. However, the error introduced by a method does not scale linearly with time step. Due to the randomness of the error, the magnitude is smaller than expected from linear scaling (see above).

\section{Conclusion}

Each of the three major filling methodologies (mean diurnal variation, look-up tables and nonlinear regression) we discussed in this paper showed good approximation of original data and small errors, when the amount of data to be filled was small, and the gap distribution random. However, some methods stayed stable even when the original gap percentage was higher.

For mean diurnal variation, these were 7-day independent window type during night, 14-day during day. Look-up tables on insolation, and air temperature during day, and soil temperature during night performed best when the data were pre-sorted into bimonthly periods. For regression methods during daytime in general we found good results with a Michaelis-Menten-type equation for temperature sorted data. However, not for all sites bimonthly periods could be maintained. Seasonal periods had to be assigned especially for sites with vast deviations from a random gap distribution. Regression methods during night gave similar results for all investigated equations and period lengths. A Lloyd \& Taylor-type equation using soil temperature as a driver, was most appropriate when applied separately for each of four seasonal periods.

Errors introduced by gap-filling did not differ much between methods, and were directly proportional to the percentage of gaps filled during a period. As they were mostly random errors, they partly compensated during time integration. For daytime, maximum observed errors were $\pm 0.20 \mathrm{~g} \mathrm{C} \mathrm{m}^{-2}$ per percentage of day filled, $\pm 0.64 \mathrm{~g} \mathrm{C} \mathrm{m}^{-2}$ per percentage of month filled, and $\pm 0.83 \mathrm{~g} \mathrm{C} \mathrm{m}^{-2}$ per percentage of year filled. The errors for nighttime gaps were in general smaller, at a maximum $\pm 0.14, \pm 0.32$ and \pm 0.52 , respectively, e.g. for a data set with $37 \%$ gaps the maximum error introduced would amount to $\pm 50 \mathrm{~g} \mathrm{C} \mathrm{m}^{-2}$ per year. However, if inter-site comparisons are performed on annual sums filled by differing methods, or $u_{*^{-}}$and not $u_{*}$-corrected data bases, the effects on annual sums due to not standardized methodology would add to the error above.

The time periods and classes we selected are empirically derived for the data sets and methods considered in this paper. Based on our experience, they can be applied to short gaps of hours to days (a maximum of 2 weeks), because the methods account for short-term 
responses. We eschew to define a gap length, above which the methods should not be applied, as this "length" would vary considerably between sites (e.g. crops compared to forests), and during the course of the year. Gaps extending in or over periods of bud-break or leaf-fall lack important information when the change in response occurred. This information cannot be inferred from the data (e.g. leaf-out turning from a source to a sink for $\mathrm{CO}_{2}$ ). "Long" gaps in this sense may require the use of a site-specific SVAT model, access to site ancillary information, or other approach that we did not consider in this paper.

The accuracy of gap filling methods depends on the pre-treatment of the data used for the parameterization of the filling algorithms, particularly when choices are made regarding $u_{*}$-correction of nighttime data. Thus, in our opinion, a re-investigation of the "nighttime"-problem, in theory and experiment, is the main prerequisite for discussing eddy covariance data. In this context, we like to emphasize vigorously the use of complementary chamber measurements of soil, stem, and leaf respiration at the tower sites.

With the data at hand, we were unable to answer which methods compared best with the artificially removed data, and under what conditions (day, night, functional group, climatic conditions). The residuals between artificially removed and filled data of various sites, methods and gap percentages could not be distinguished by ANOVA. This is mostly due to the overall scatter of eddy covariance data that built the basis for the artificial data removing. Which filling methods are best under drought conditions, particularly for semi-arid systems, was not investigated, as soil water measurements were only available for four sites. However, if drought coincides with the seasonal period-setup, then its effect will be captured by a separate parameterization of the lookup table, or regression method. It will be captured by mean diurnal variation, if the window length matches drought periods.

The decision about which filling strategy is most applicable might be still in the hand of the principle investigators. However, synthesis issues in progress should be based on data sets comparable in terms of data rejection, and filling strategies. The results reported here emphasize the importance of method standardization during this data post-processing phase. For comparison with output of SVAT models driven by meteorological conditions, the preservation of responses to temperature, insolation, etc. by the chosen method is advantageous. Thus, look-up tables or regression methods should be preferred. Standardization should be applied to carbon, as well as sensible and latent heat fluxes, to provide for consistent data bases for a suite of potential users.

This work contributes to the efforts of the flux community collecting continuous measurements of ecosystem carbon and energy exchange by compiling consistent, quality assured, and documented data sets from a variety of worldwide ecosystems. Standardization in the data post-processing assures justified comparable data to address inter-comparisons across natural and managed ecosystems, climatic gradients, and multiple years, and to investigate the processes controlling carbon and energy fluxes of these systems.

\section{Acknowledgements}

This work is supported by NASA's EOS Validation Project and contributes to the EUROFLUX, AmeriFlux, and FLUXNET programs. We also acknowledge and appreciate funding for the numerous sites by the European Union (EUROFLUX project), US Department of Energy's Terrestrial Carbon Program, and NIGEC Program (AmeriFlux projects). We thank the anonymous technicians at 18 sites in Europe and the US for their assistance in the acquisition of the field data.

\section{Appendix A}

\section{A.1. Algorithms of gap filling routines}

\section{A.1.1. Mean diurnal variation}

For each subsequent period of data (independent window) or a window of prescribed size around each gap (gliding window) mean diurnal variation, i.e. bin-averages of half hours during the period were calculated to fill gaps within the respective period. 
A.1.1.1. Independent window.

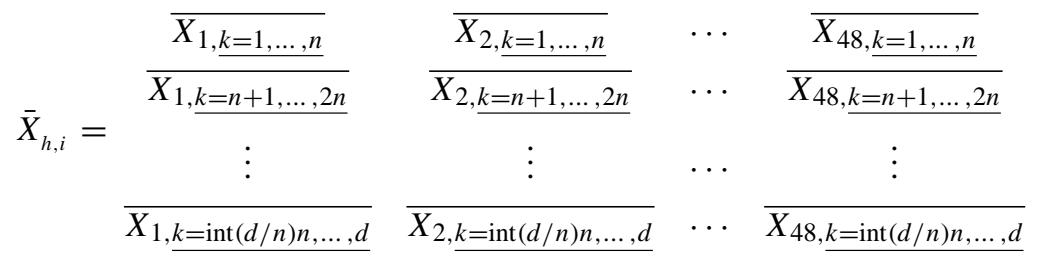

where $h$ is the index for the half-hour $(h=1, \ldots$, 48), $i$ the index for the averaging window with $i=$ $1, \ldots$, integer $(d / n)+1, n$ is the window size, and $d$ the number of days per year. An overbar indicates averaging of the data subspace, underlining of indices elimination of missing values in the subspace. The last subspace for each half-hour is smaller, as $d / n$ usually is real.
Fitting $T_{0}$ however, adds a degree of freedom to the regression and lead to closer estimates for our sites. Arrhenius (Lloyd and Taylor, 1994, their Eq. (8))

$F_{\mathrm{RE}, \text { night }}=F_{\mathrm{RE}, \operatorname{Tref}} \mathrm{e}^{\left[E_{\mathrm{a}} / R\left(\left(1 / T_{\mathrm{ref}}\right)-\left(1 / T_{\mathrm{K}}\right)\right)\right]}$

Here $F_{\mathrm{RE}, T r e f}$ and $E_{\mathrm{a}}$ are the fitted parameters, $E_{\mathrm{a}}$ the activation energy in $\mathrm{J} \mathrm{mol}^{-1}, R$ the gas constant $\left(8.134 \mathrm{~J} \mathrm{~K}^{-1} \mathrm{~mol}^{-1}\right)$.

\section{A.1.1.2. Gliding window.}

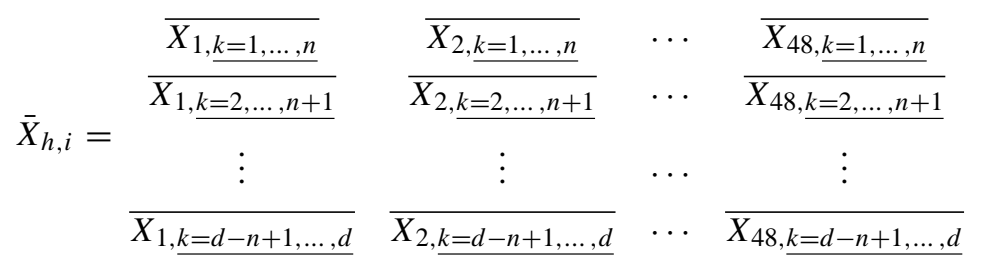

as above, but the window index, $i$, ranges from 1 to $(d-n+1)$, and all subspaces have the same size.

Nonlinear regression methods (for $F_{\mathrm{NEE}}$ only) are described as follows.

A.1.1.3. Respiration equations. The respiration equations based on Lloyd and Taylor (1994) used as reference temperature $\left(T_{\text {ref }}\right) 298.16 \mathrm{~K}$. Depending on the defined filling procedure, the temperature was either air temperature or soil temperature in a depth of $5 \mathrm{~cm}$.

Lloyd \& Taylor (Lloyd and Taylor, 1994, their Eq. (11))

$F_{\mathrm{RE}, \text { night }}=F_{\mathrm{RE}, \operatorname{Tref}} \mathrm{e}^{\left[E_{0}\left(1 /\left(T_{\mathrm{ref}}-T_{0}\right)\right)-\left(1 /\left(T_{\mathrm{K}}-T_{0}\right)\right)\right]}$

In the application the parameter $E_{0}$ is set to $309 \mathrm{~K}$, whereas the parameters $T_{0}$ and $F_{\mathrm{RE} \text {,Tref }}$, the respiration rate at $T_{\text {ref }}$, were fitted to the respective data subset. $T_{\mathrm{K}}$ is air or soil temperature (in $\mathrm{K}$ ). Lloyd and Taylor (1994) found a set of $E_{0}$ and $T_{0}$ general applicable for soil respiration of various ecosystems.
Van't Hoff (Lloyd and Taylor, 1994, their Eq. (4))

$$
F_{\text {RE,night }}=A \mathrm{e}^{(B T)}
$$

This equation can be re-written as a Q10 relationship with $B=\ln (\mathrm{Q} 10) / 10$ (temperature is in ${ }^{\circ} \mathrm{C}$ here, for further details see Lloyd and Taylor, 1994). Therefore, we excluded a Q10 function from the analysis.

A.1.1.4. Equation for temperature dependence of $F_{G P P, \text { opt }} . \quad F_{\mathrm{GPP}, \mathrm{opt}}$, the gross primary productivity at "optimum" light but evaluated for separate temperature classes, was found showing an optimum response to temperature, and is described as follows:

Johnson (Johnson et al., 1942, modified after Harley and Tenhunen, 1991)

$$
\begin{aligned}
F_{\mathrm{GPP}, \text { opt }}= & \frac{F_{\mathrm{GPP}, \operatorname{Tref}} \mathrm{e}^{\left(\Delta H_{\mathrm{a}}\left(T_{\mathrm{K}}-T_{\text {ref }}\right) /\left(R T_{\mathrm{K}} T_{\text {ref }}\right)\right)}}{1+\mathrm{e}^{\left(\left(\Delta S T_{\mathrm{K}}-\Delta H_{\mathrm{d}}\right) /\left(R T_{\mathrm{K}}\right)\right)}} \\
& \times\left(1+\mathrm{e}^{\left(\left(\Delta S T_{\text {ref }}-\Delta H_{\mathrm{d}}\right) /\left(R T_{\text {ref }}\right)\right)}\right)
\end{aligned}
$$

Here $T_{\mathrm{K}}$ is air temperature (in $\mathrm{K}$ ), $R$ again the gas constant, $\Delta H_{\mathrm{a}}$ the activation energy in $\mathrm{J} \mathrm{mol}^{-1}, \Delta H_{\mathrm{d}}$ 
the energy of deactivation (set to $215,000 \mathrm{~J} \mathrm{~mol}^{-1}$ ), $\Delta S$ an entropy term (set to $730 \mathrm{~J} \mathrm{~K}^{-1} \mathrm{~mol}^{-1}$ ) and $F_{\mathrm{GPP}}$, Tref the carbon uptake at optimum light and the reference temperature $T_{\text {ref }}(298.16 \mathrm{~K})$.

A.1.1.5. Light response equations. The equations describe potential shapes of ecosystem light responses, and use the following terms in common: $Q_{\text {PPFD }}$ is the photosynthetic photon flux density ( $\mu$ mol quantum $\mathrm{m}^{-2} \mathrm{~s}^{-1}$ ), $a^{\prime}$ the ecosystem quantum yield $\left(\mu \mathrm{mol} \mathrm{CO}_{2} \mathrm{~m}^{-2} \mathrm{~s}^{-1}\right)$ ( $\mu$ mol quantum m $\mathrm{m}^{-2} \mathrm{~s}^{-1}$ ). $F_{\mathrm{GPP} \text {,opt }}$ is the gross primary productivity at "optimum" light $\left(\mu \mathrm{mol} \mathrm{CO} \mathrm{m}^{-2} \mathrm{~s}^{-1}\right.$, see above); $F_{\mathrm{GPP}, \text { sat }}$ is the gross primary productivity at "saturating" light $\left(\mu \mathrm{molCO} \mathrm{m}^{-2} \mathrm{~s}^{-1}\right) . F_{\mathrm{RE}, \text { day }}$ is the ecosystem respiration during the day, and $F_{\mathrm{NEE}}$ the net ecosystem exchange (both $\mu \mathrm{mol} \mathrm{CO} \mathrm{C}^{-2} \mathrm{~s}^{-1}$ ).

Smith (Smith, 1938)

$F_{\mathrm{NEE}}=\frac{a^{\prime} Q_{\mathrm{PPFD}} F_{\mathrm{GPP}, \mathrm{opt}}}{\sqrt{\left(F_{\mathrm{GPP}, \mathrm{opt}}\right)^{2}+\left(a^{\prime} Q_{\mathrm{PPFD}}\right)^{2}}}-F_{\mathrm{RE}, \mathrm{day}}$

Michaelis-Menten (Michaelis and Menten, 1913, elsewhere referred to as rectangular hyperbola).

Ordinarily, the formulation is

$F_{\mathrm{NEE}}=\frac{a^{\prime} Q_{\mathrm{PPFD}} F_{\mathrm{GPP}, \mathrm{sat}}}{F_{\mathrm{GPP}, \text { sat }}+a^{\prime} Q_{\mathrm{PPFD}}}-F_{\mathrm{RE}, \text { day }}$

The saturation value $F_{\mathrm{GPP} \text {, sat }}$ of this equation only applies when $Q_{\text {PPFD }} \rightarrow \infty$, a value of less explanatory worth for real systems. Therefore, we applied a form where $F_{\mathrm{GPP} \text {,opt }}$ is the rate at a $Q_{\mathrm{PPFD}}$ value of $2000 \mu \mathrm{mol} \mathrm{m}^{-2} \mathrm{~s}^{-1}$.

$$
\begin{aligned}
F_{\mathrm{NEE}}= & \frac{a^{\prime} Q_{\mathrm{PPFD}}}{\left(1-\left(Q_{\mathrm{PPFD}} / 2000\right)+\left(a^{\prime} Q_{\mathrm{PPFD}} / F_{\mathrm{GPP}, \mathrm{opt}}\right)\right)} \\
& -F_{\mathrm{RE}, \text { day }}
\end{aligned}
$$

Misterlich (adapted after Dagnelie, 1991)

$$
\begin{aligned}
F_{\mathrm{NEE}}= & F_{\mathrm{GPP}, \text { opt }}\left(1-\mathrm{e}^{\left(\left(a^{\prime} Q_{\mathrm{PPED}}\right) /\left(F_{\mathrm{GPP}, \mathrm{opt}}\right)\right)}\right) \\
& -F_{\mathrm{RE}, \text { day }}
\end{aligned}
$$

\section{Appendix B. $\mathbf{u}_{*}$-correction}

The correction of nighttime eddy covariance fluxes under stable conditions at the moment seems the engineering approach to deal with uncertainties in eddy diffusivity at night, suspected by numerous researchers (see Lee, 1998; Baldocchi et al., 2000a for references). The correction is based on extrapolating nighttime eddy covariance fluxes derived for higher turbulence into periods of more stable conditions. The procedure simultaneously normalizes the fluxes for soil temperature, which is viewed as one of the major drivers for nighttime fluxes. One of several exponential equations on soil temperature (see respiration functions above) will be evaluated for nighttime data sorted for friction velocity ( $u_{*}$, for instance $0.05 \mathrm{~m} \mathrm{~s}^{-1}$-classes), fitting the parameter describing the flux $F_{\mathrm{RE}, 283}$ at the reference temperature $(283 \mathrm{~K})$ and keeping all the other parameters constant. The derived values for $F_{\mathrm{RE}, 283}$ will be investigated as a function of $u_{*}$, and normally show a typical saturation above a certain $u_{*}$-threshold. The saturated value of $F_{\mathrm{RE}, 283}$ then will be used as a parameter to compute corrected nighttime fluxes for periods, where $u_{*}$ is below the threshold (see Goulden et al., 1996b; Aubinet et al., 2000). The point, where methods differ, is whether it should be applied for the genuine eddy covariance flux or the flux, which is already corrected for the so-called storage term. The storage term accounts for the change of $\mathrm{CO}_{2}$ concentration inside the canopy air volume, generally an accumulation during stable conditions during night and a release during more turbulent periods in the morning. We applied the $u_{*}$-correction to storage-corrected fluxes (if available, see Table 8), as for ideal terrain (no advection) the consideration of storage changes should have accounted for non-biological $\mathrm{CO}_{2}$ accumulation due to low turbulence during night, and non-biological $\mathrm{CO}_{2}$ release during day. If still smaller $F_{\mathrm{RE}, 283}$ are observed for low $u_{*}$ at night, then the method corrects for it. The storage term is added during day and night, and sums to approximately zero over the year, so we do not have to account for double-counting of storage as discussed by Aubinet et al. (2000). For the sites with given storage measurements our correction considers only the residual underestimation of $F_{\mathrm{RE}, 283}$, and was implemented as described above using the Arrhenius equation (Eq. (A.4)) with parameter $E_{\mathrm{a}}$ computed first for the entire data set, and then 
held constant. For sites without storage measurements, i.e. HL, HV, and DU, the $u_{*}$-correction - if applied - leads to double-counting of the storage term, i.e. during night accounted for within the $u_{*}$-correction, during day implicitly measured by eddy correlation, but not corrected for. Their daytime $F_{\text {NEE }}$ therefore should amount to somewhat more negative numbers. The parameters and $u_{*}$-threshold are given in Table 8 . Effects of seasonality or soil-water availability during the normalization were neglected.

\section{Appendix C. Details on the error analysis for all filling methods}

The absolute error as the difference between original measurements and the filled-in value for the different methods serves as a measure of the performance of a method. Mean errors, the standard deviation from the mean, skewness and kurtosis of the error distribution were calculated for all four sites HY97, HV96, SH97, and BV97, and each level of artificial gaps for a variety of combinations of filling methods and data set pre-treatments.

Using mean diurnal variation as filling method, we combined applications of gliding or independent windows with window sizes of 7 or 14 days and two data pre-treatments (a priori merging to hourly time step, or filling of single half-hourly gaps by linear interpolation). The lowest absolute errors and small kurtosis values were found when applying independent window and 14-day averaging period during daytime, and a 7-day averaging during nighttime. These two methods are referred to as "MDV" for "mean diurnal variation" in the main text.

Applying look-up table methods, we tested sorting by $T_{\mathrm{s}}$ or $T_{\mathrm{a}}$ in combination with different period lengths (bimonthly, or four seasonal periods) for nighttime data, and sorting by $Q_{\mathrm{PPFD}}$ and $T_{\mathrm{a}}$ in combination with sorting according to sky clearness indices and different period lengths. The best results were associated with the look-up table method, when data were restricted to daytime periods and were sorted by radiation and air temperature for bimonthly periods. During nighttime, sorting by air temperature within each bimonthly period yield more accurate results than sorting by soil temperature. But this conclusion holds only for data sets with low gap percentages. For gap per- centage of $45 \%$ and larger during the night, methods sorting by soil temperature are more stable. We called these methods "LookUp" in the main text.

Within the group of nonlinear regressions we tested three equations for nighttime respiration (see Appendix A.1) in combination with different period lengths (as above), different forcing variables $\left(T_{\mathrm{s}}\right.$ or $\left.T_{\mathrm{a}}\right)$, and for $u_{*^{-}}$or not $u_{*}$-corrected values. For daytime data, selected combinations of Michaelis-Menten or Misterlich equation, different period lengths, pre-sorting by clearness index and different levels of pooling of data were investigated. Pooling levels included (a) data pooled for all temperature classes of a given period; (b) a priori sub-sorting of data into $4{ }^{\circ} \mathrm{C}$ temperature classes and (c) a combined determination of parameters describing light, and temperature response. For daytime data the lowest absolute error and small skewness and kurtosis values were associated with a technique that evaluated the Michaelis-Menten light response curve for various air temperature classes. Periods of 2 months can be successfully applied for data sets with almost randomly distributed gaps. They will fail for data sets with long-term system breakdowns, i.e. longer than 2 months. Then seasonal periods must be assigned for the gap filling, and site-specific information on season length must be provided.

Whether we correct eddy fluxes for friction velocity or not during night does not affect the mean error, as it remains close to zero. On the other hand, it has a major impact on the skewness and kurtosis of the data sets. The performance of Eqs. (A.3)-(A.5) (Lloyd \& Taylor, Arrhenius, and Van't Hoff), and sorting into bimonthly or four-seasonal periods could not be distinguished, and we decided to use Eq. (A.3) for each of four seasons. Using air temperature as driver gave slightly better results at the $35 \%$ gap level, but went unstable for higher gap percentages, so we preferred soil temperature as driving variable. In the end we decided to use soil temperature as driver for both $u_{*}$-corrected values, and not $u_{*}$-corrected values.

\section{References}

Anthoni, P.M., Law, B.E., Unsworth, M.H., 1999. Carbon and water vapor exchange of an open-canopied ponderosa pine ecosystem. Agric. For. Meteorol. 95, 151-168. 
Aubinet, M., Grelle, A., Ibrom, A., Rannik, Ü., Moncrieff, J., Foken, T., Kowalski, A.S., Martin, P.H., Berbigier, P., Bernhofer, Ch., Clement, R., Elbers, J., Granier, A., Grünwald, T., Morgenstern, K., Pilegaard, K., Rebmann, C., Snijders, W., Valentini, R., Vesala, T., 2000. Estimates of the annual net carbon and water exchange of forests: the EUROFLUX methodology. Adv. Ecol. Res. 30, 113-175.

Baldocchi, D.D., 1997. Measuring and modeling carbon dioxide and water vapor exchange over a temperate broad-leaved forest during the 1995 summer drought. Plant, Cell Environ. 20, 11081122.

Baldocchi, D.D., Valentini, R., Running, S.R., Oechel, W., Dahlman, R., 1996. Strategies for measuring and modelling carbon dioxide and water fluxes over terrestrial ecosystems. Global Change Biol. 2, 159-168.

Baldocchi, D.D., Finnigan, J., Wilson, K., Paw, U.K.T., Falge, E., 2000a. On measuring net ecosystem carbon exchange over tall vegetation on complex terrain. Boundary Layer Meteorol. 96, 257-291.

Baldocchi, D.D., Falge, E., Wilson, K., 2000b. A spectral analysis of biosphere-atmosphere trace gas flux densities and meteorological variables across hour to year time scales. Agric. For. Meteorol., in press.

Bowling, D.R., Baldocchi, D.D., Monson, R.K., 1999. Dynamics of isotope exchange of carbon dioxide in a Tennessee deciduous forest. Global Biogeochem. Cycles 13, 903-921.

Clark, K.L., Gholz, H.L., Moncrieff, J.B., Cropley, F., Loescher, H.W., 1999. Environmental controls over net exchanges of carbon dioxide from contrasting Florida ecosystems. Ecol. Appl. 9, 936-948.

Chen, W.J., Black, T.A., Yang, P.C., Barr, A.G., Neumann, H.H., Nesic, Z., Blanken, P.D., Novak, M.D., Eley, J., Ketler, R.J., Cuenca, R., 1999. Effects of climatic variability on the annual carbon sequestration by a boreal aspen forest. Global Change Biol. 5, 41-54.

Dagnelie, P., 1991. Théorie et Méthodes Statistiques, Vol. 1. Presses Agronomiques de Gembloux, Gembloux, Belgium.

Edwards, N.T., Shugart, H.H., Jr., McLaughlin, S.B., Harris, W.F., Reichle, D.E., Reichle, D.E., 1981. Carbon metabolism in terrestrial ecosystems. In: Dynamic Properties of Forest Ecosystems. Cambridge University Press, Cambridge, UK, pp. 499-536.

Ehleringer, J., Björkman, O., 1977. Quantum yields for $\mathrm{CO}_{2}$ uptake in $\mathrm{C}_{3}$ and $\mathrm{C}_{4}$ plants. Plant Physiol. 59, 86-90.

Foken, Th., Wichura, B., 1995. Tools for quality assessment of surface-based flux measurements. Agric. For. Meteorol. 78, 83105 .

Gifford, R.M., 1994. The global carbon cycle: a viewpoint on the missing sink. Aust. J. Plant Physiol. 21, 1-15.

Goetz, S.J., Prince, S.D., 1998. Variability in carbon exchange and light utilization among boreal forest stands: implications for remote sensing of net primary production. Can. J. For. Res. 28, 375-389.

Goulden, M.L., Munger, J.W., Fan, S.M., Daube, B.C., Wofsy, S.C., 1996a. Exchange of carbon dioxide by a deciduous forest: response to interannual climate variability. Science 271, 15761578.
Goulden, M.L., Munger, J.W., Fan, S.M., Daube, B.C., Wofsy, S.C., 1996b. Measurement of carbon storage by long-term eddy correlation: Methods and a critical assessment of accuracy. Global Change Biol. 2, 169-182.

Granier, A., Ceschia, E., Damesin, C., Dufrêne, E., Epron, D., Gross, P., Lebaube, S., Le Dantec, V., Le Goff, N., Lemoine, D., Lucot, E., Ottorini, J.M., Pontailler, J.Y., Saugier, B., 2000. The carbon balance of a young beech forest. Funct. Ecol. 14, 312-325.

Greco, S., Baldocchi, D.D., 1996. Seasonal variations of $\mathrm{CO}_{2}$ and water vapour exchange rates over a temperate deciduous forest. Global Change Biol. 2, 183-198.

Grünwald, Th., Bernhofer, Ch., 2000. Regression modelling used for data gap filling of carbon flux measurements. In: Ceulemans, R.J.M., Veroustraete, F., Gond, V., Van Rensbergen, J.B.H.F. (Eds.), Forest Ecosystem Modelling, Upscaling And Remote Sensing. SPB Academic Publishing, The Hague, The Netherlands, pp. 61-67.

Gu, L., Fuentes, J.D., Shugart, H.H., Staebler, R.M., Black, T.A., 2000. Responses of net ecosystem exchanges of carbon dioxide to changes in cloudiness: results from two North American deciduous forests. J. Geophys. Res. 104, 31421-31434.

Harley, P.C., Tenhunen, J.D., 1991. Modeling the photosynthetic response of $\mathrm{C}_{3}$ leaves to environmental factors. In: Boote, K.J., Loomis, R.S. (Eds.), Proceedings of the ASA (American Society of Agronomy and Crop Science Society of America) Symposium on Modeling Crop Photosynthesis - From Biochemistry to Canopy, Madison, WI, pp. 17-39.

Hollinger, D.Y., Kelliher, F.M., Byers, J.N., Hunt, J.E., McSeveny, T.M., Weir, P.L., 1994. Carbon dioxide exchange between an undisturbed old-growth temperate forest and the atmosphere. Ecology 75, 134-150.

Hollinger, D.Y., Anthoni, P.M., Bakwin, P., Baldocchi, D.D., Berger, B.W., Davis, K., Falge, E., Fuentes, J.D., Law, B.E., Lee, X., Meyers, T.P., Munger, J.W., Staebler, R., Suyker, A., Unsworth, M.H., Verma, Sh., Yi, Ch., 2000. AmeriFlux: Initial results from a network of long-term, terrestrial $\mathrm{CO}_{2}$ flux measurement sites. In preparation.

Jarvis, P.G., James, G.B., Landsberg, J.J., 1976. Coniferous forest. In: Monteith, J.L. (Ed.), Vegetation and the Atmosphere, Vol. II. Case Studies, Academic Press, London, pp. 171-240.

Jarvis, P.G., Massheder, J., Hale, D., Moncrieff, J., Rayment, M., Scott, S., 1997. Seasonal variation of carbon dioxide, water vapor and energy exchanges of a boreal black spruce forest. J. Geophys. Res. 102, 28953-28967.

Johnson, F., Eyring, H., Williams, R., 1942. The nature of enzyme inhibitions in bacterial luminescence: sulfanilamide, urethane, temperature, and pressure. J. Cell Comp. Physiol. 20, 247-268.

Katul, G.G., Lai, C.T., Schäfer, K.V., Vidakovic, B., Albertson, J.D., Ellsworth, D., Oren, R., 2000. Multiscale analysis of vegetation surface fluxes: from seconds to years. Special Issue on Nonlinear Propagation of Multi-Scale Dynamics through Hydrologic Subsystems. Adv. Water Resourc. (in review).

Kowalski, A.S., Overloop, S., Ceulemans, R., 1999. Eddy fluxes above a Belgian, Campine forest and relationships with predicting variables. In: Ceulemans, R., Veroustraete, F., Gond, V., Van Rensbergen, J. (Eds.), Forest Ecosystem Modelling, 
Upscaling And Remote Sensing, SPB Publishing, The Hague, pp. 3-18.

Law, B.E., Baldocchi, D.D., Anthoni, P.M., 1999a. Below-canopy and soil $\mathrm{CO}_{2}$ fluxes in a ponderosa pine forest. Agric. For. Meteorol. 94, 171-188.

Law, B.E., Ryan, M.G., Anthoni, P.M., 1999b. Seasonal and annual respiration of a ponderosa pine ecosystem. Global Change Biol. $5,169-182$.

Law, B.E., Waring, R.H., Aber, J.D., Anthoni, P.M., 2000. Measurements of gross and net ecosystem productivity and water vapor exchange of a Pinus ponderosa ecosystem, and an evaluation of two generalized models. Global Change Biol. 6, $155-168$.

Lee, X., 1998. On micrometeorological observations of surface-air exchange over tall vegetation. Agric. For. Meteorol. 91, 39-50.

Lloyd, J., Taylor, J.A., 1994. On the temperature dependence of soil respiration. Funct. Ecol. 8, 315-323.

Mahrt, L., 1998. Flux sampling errors for aircraft and towers. J. Atmos. Oceanic Technol. 15, 416-429.

McMillen, R.T., 1988. An eddy correlation technique with extended applicability to non-simple terrain. Boundary Layer Meteorol. 43, 231-245.

Michaelis, L., Menten, M.L., 1913. Die Kinetik der Invertinwirkung. Biochem. Z. 49, 333.

Moncrieff, J.B., Mahli, Y., Leuning, R., 1996. The propagation of errors in long term measurements of land atmosphere fluxes of carbon and water. Global Change Biol. 2, 231-240.

Moncrieff, J.B., Massheder, J.M., de Bruin, H., Elbers, J., Friborg, T., Heusinkveld, B., Kabat, P., Scott, S., Sogaard, H., Verhoef, A., 1997. A system to measure surface fluxes of momentum, sensible heat, water vapour and carbon dioxide. J. Hydrol. 188/189, 589-611.

Pilegaard, K., Hummelshøj, P., Jensen, N.O., Chen, Z., 2000. Two years of continuous $\mathrm{CO}_{2}$ eddy flux measurements over a Danish beech forest. Agric. For. Meteorol. (EUROFLUX Special Issue), in press.
Raich, J.W., Schlesinger, W.H., 1992. The global carbon dioxide flux in soil respiration and its relationship to vegetation and climate. Tellus 44B, 81-99.

Ruel, J.J., Ayres, M.P., 1999. Jensen's inequality predicts effects of environmental variation. Trends Ecol. Evolution 14, 361366.

Ruimy, A., Jarvis, P.G., Baldocchi, D.D., Saugier, B., 1995. $\mathrm{CO}_{2}$ fluxes over plant canopies and solar radiation: a review. Adv. Ecol. Res. 26, 1-63.

Running, S.W., Baldocchi, D.D., Turner, D., Gower, S.T., Bakwin, P., Hibbard, K., 1999. A global terrestrial monitoring network, scaling tower fluxes with ecosystem modeling and EOS satellite data. Remote Sens. Environ. 70, 108-127.

Ryan, M.G., 1991. A simple method for estimating gross carbon budgets for vegetation in forest ecosystems. Tree Physiol. 9, 255-266.

Smith, E., 1938. Limiting factors in photosynthesis: light and carbon dioxide. Gen. Physiol. 22, 21-35.

Valentini, R., de Angelis, P., Matteucci, G., Monaco, R., Dore, S., Scarascia-Mugnozza, G.E., 1996. Seasonal net carbon dioxide exchange of a beech forest with the atmosphere. Global Change Biol. 2, 199-208.

Valentini, R., Matteucci, G., Dolman, A.J., Schulze, E.-D., Rebmann, C., Moors, E.J., Granier, A., Gross, P., Jensen, N.O., Pilegaard, K., Lindroth, A., Grelle, A., Bernhofer, C., Grünwald, T., Aubinet, M., Ceulemans, R., Kowalski, A.S., Vesala, T., Rannik, Ü., Berbigier, P., Loustau, D., Guðmundsson, J., Thorgeirsson, H., Ibrom, A., Morgenstern, K., Clement, R., Moncrieff, J., Montagnani, L., Minerbi, S., Jarvis, P.G., 2000. Respiration as the main determinant of carbon balance in European forests. Nature 404, 861-865.

Waring, R.H., Landsberg, J.J., Williams, M., 1998. Net primary production of forests: a constant fraction of gross primary production? Tree Physiol. 18, 129-134. 